Supporting Information

\title{
Interstitially Mixed Self-Assembled Monolayers Enhance Electrical Stability of Molecular Junctions
}

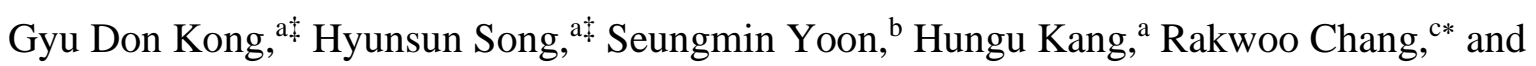
Hyo Jae Yoon ${ }^{\text {a* }}$

${ }^{a}$ Department of Chemistry, Korea University, Seoul, 02841, Korea

${ }^{\mathrm{b}}$ Department of Chemistry, Kwangwoon University, Seoul, 01897, Korea

${ }^{c}$ Department of Applied Chemistry, University of Seoul, Seoul, 02543, Korea

Corresponding authors’ email: rchang90@uos.ac.kr (R.C), hyoon@korea.ac.kr (H.J.Y.)

These authors contributed to this work equally. 


\section{$\underline{\text { Table of Contents }}$}

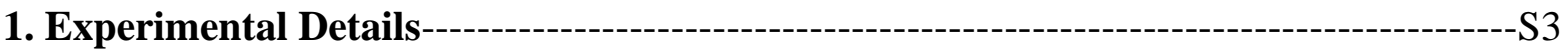

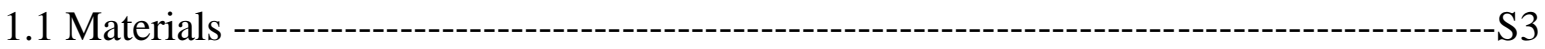

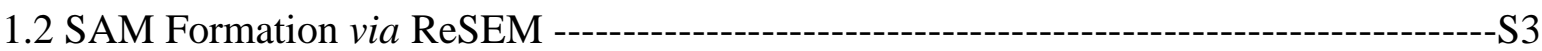

2. Breakdown Voltage Measurements and Data Analysis -----o---S4

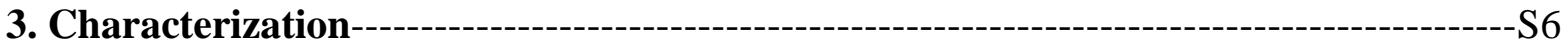

3.1 Static and Dynamic Water Contact Angle Measurements --------------------------------S6

3.2 X-ray Photoelectron Spectroscopy (XPS) Analysis ------------------------------------S7

3.3 Percent Electrochemically Active Surface Area (\%EAS) Analysis -----------------------S7

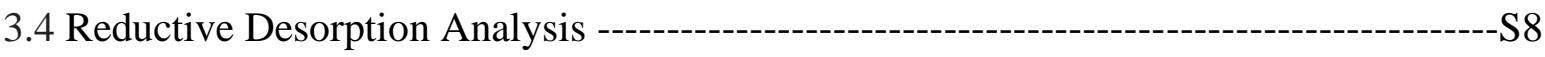

3.5 Electrochemical Impedance Spectroscopy (EIS) Analysis----------------------------S9

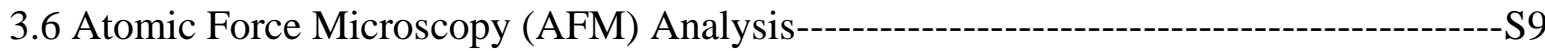

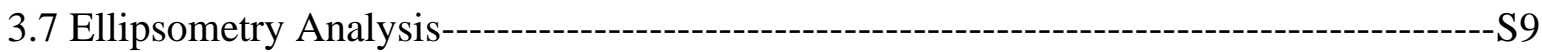

3.8 Near Edge X-ray Adsorption Fine Structure Spectroscopy (NEXAFS) Analysis ------S10

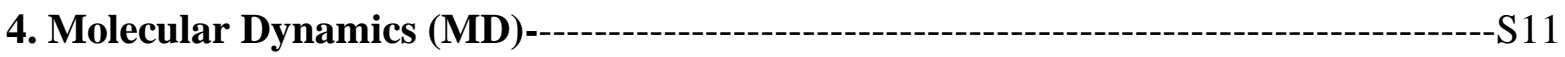

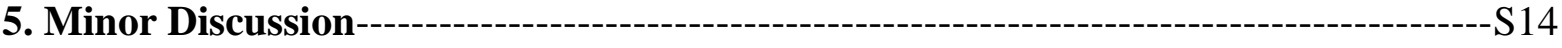

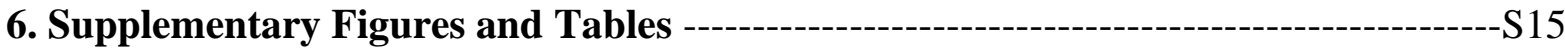

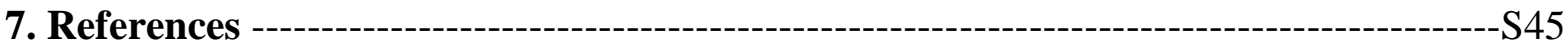




\section{Experimental Details}

\subsection{Materials}

All reagents were used as supplied unless otherwise specified. All organic solvents were purchased from Sigma-Aldrich and Daejung while water was purified using an Aqua MAX-Basic System (deionized water, the electrical resistivity of which is $\sim 18.2 \mathrm{M} \Omega \cdot \mathrm{cm}$ ). Octanethiol $\left(\mathrm{HSC}_{8}\right)$ were purchased from TCI (>95\%). High purity eutectic gallium-indium (EGaIn; 99.99\%) was obtained from Sigma-Aldrich and used as supplied. 2,2'-Bipyridylterminated $n$-undecanethiol $\left(\mathrm{HS}\left(\mathrm{CH}_{2}\right)_{11} \mathrm{BIPY}\right)$ was synthesized following the procedures reported in the literature. ${ }^{1}$ All thiol derivatives were stored under $\mathrm{N}_{2}$ atmosphere and $<4{ }^{\circ} \mathrm{C}$. Silver and gold thin films $(\sim 300 \mathrm{~nm})$ were deposited onto silicon wafer (100 mm in diameter; 1-10 ohm-cm, $525 \pm 50$ microns thick) by e-beam evaporator (ULVAC). For templatestripping, photo-curable polymer was purchased from Norland (NOA81) and used as supplied.

\subsection{SAM Formation via ReSEM}

The ReSEM method consists of the following steps. i) Freshly prepared ultraflat template-stripped gold $\left(\mathrm{Au}^{\mathrm{TS}}\right)$ chip ${ }^{2}$ was immersed in a degassed ethanol (anhydrous, 99.9\%) solution containing $1 \mathrm{mM} \mathrm{HSC}{ }_{11}$ BIPY. After $3 \mathrm{~h}$ incubation under $\mathrm{N}_{2}$ atmosphere at room temperature, the SAM-bound $\mathrm{Au}^{\mathrm{TS}}$ chip was thoroughly rinsed with ethanol. ii) Next, the resulting SAM was immersed in an ethanol solution containing $1 \mathrm{mM} \mathrm{HSC}_{8}$. After incubation for $3 \mathrm{~h}$ under $\mathrm{N}_{2}$ atmosphere at room temperature, the SAM was rinsed with pure ethanol. iii) The resulting SAM was further incubated with an ethanol solution of $1 \mathrm{mM} \mathrm{HSC}{ }_{11} \mathrm{BIPY}$ for $18 \mathrm{~h}$ in $\mathrm{N}_{2}$ atmosphere. The last two steps are defined as one cycle in the ReSEM. The cycle is repeated till $V_{\mathrm{BD}}$ reaches a plateau or the highest value, and the value of $r^{+}$is maximized or similar to that of pure $\mathrm{SC}_{11} \mathrm{BIPY}$ SAM. 


\section{Breakdown Voltage Measurements and Data Analysis}

EGaIn tip fabrication, and junction formation and measurements were done following the method reported in the literature. ${ }^{1,3}$ A conical tip of EGaIn for use as a top contact was formed following the method reported in the literature. ${ }^{2,4}$ Briefly, a $10 \mu \mathrm{L}$ gas-tight syringe was filled with EGaIn ( $\geq 99.99 \%$, Aldrich). A drop of EGaIn was pushed to the tip of the syringe needle, the hanging drop was brought into contact with a surface on which the EGaIn could stick (e.g., an oxidized Ag surface), and the needle gently pulled away from the drop using a micromanipulator. Upon breaking from the bulk EGaIn on the surface, a conical tip was obtained. A conical tip of EGaIn was newly formed every junction in order to eliminate complexities that may arise from contamination of the EGaIn surface by volatile organics in air. In cases that visible whiskers formed during tip fabrication, the tip was discarded, and a new tip was formed.

With a freshly prepared EGaIn conical tip, a junction with the structure, $\mathrm{Au}^{\mathrm{TS}} / \mathrm{SAM} / / \mathrm{Ga}_{2} \mathrm{O}_{3} / \mathrm{EGaIn}$ (“/” and "//" correspond to covalent and van der Waals contacts, respectively), was formed, and three $J$ - $V$ traces were measured at $\pm 0.50 \mathrm{~V}$ to make sure the reliable contact formation. Then, a voltage sweep from zero to either of sufficiently high $+V$ or $-V$ (here, $+10.0 \mathrm{~V}$ and $-10.0 \mathrm{~V}$ ) with a step size of $|0.2 \mathrm{~V}|$ was applied to the junction until a sharp increase of $J$ occurred by several orders of magnitude and current $(I, \mathrm{~A})$ reached the maximum set value of electrometer, $105 \mathrm{~mA}$ (which was defined as the short). Figure S16 shows representative $J-V$ traces and determination of $V_{\mathrm{BD}}$ values. We repeated this experiment for many separate junctions to obtain $V_{\mathrm{BD}}$ histograms from which mean $\left(\mu^{V_{\mathrm{BD}}}\right)$ and standard deviation $\left(\sigma^{V_{\mathrm{BD}}}\right)$ values were extracted. 
For measuring $J(V)$ and rectification ratios, we used the same EGaIn junctions. All junction formation and measurements were carried out in ambient conditions. The SAM-bound bottom electrode was grounded, and the EGaIn top electrode was biased. The diameter of the contact area was measured at high magnification. Assuming a circular contact, the area was derived from the measured diameter from which the current densities $\left(J, \mathrm{~A} / \mathrm{cm}^{2}\right)$ were calculated. The contact and presence of a SAM was confirmed by running a single $J-V$ scan after which 20 more scans were run if there was indication of contact and tunneling. A trace is based on the following voltage sweep sequence: $0 \mathrm{~V} \rightarrow+\mathrm{V} \rightarrow 0 \mathrm{~V} \rightarrow-\mathrm{V} \rightarrow 0 \mathrm{~V}$. Therefore, one trace corresponds to two scans. The total number of working junctions versus those that shorted was used to calculate the yield (\%) of working junctions. Shorts were excluded prior to analysis. ${ }^{5}$ Shorts clearly do not give information about the SAM and can bias distributions of current density toward high values. Thus, when one performs operations on the raw distribution of $\log$-current density $(\log |J|)$, one discards values corresponding to shorts. Shorts are defined as values of current that reach the compliance limit of our electrometer $( \pm 0.105 \mathrm{~A})$. For generating histograms, we kept the bin-size of $r$ histograms constant, making the resolution of mean values (the width of each bean is $\sim 0.2$ in a log-scale). 


\section{Characterization}

\subsection{Static and Dynamic Water Contact Angle Measurements}

The measurement of static contact angle is a useful tool to study the structure and chemistry of the outermost few angstroms of a surface. Thus, the quality of the SAM can be estimated from the contact angle measurement results. The static contact angle $\left(\theta_{\mathrm{s}}\right)$ is measured by dropping a liquid droplet onto a SAM. When the droplet is placed on the surface, the angle between the tangent and the solid surface is measured as illustrated in Figure S5. The relationship between the free energy of the surface and a contact angle, $\theta_{\mathrm{s}}$, is described by Young's equation:

$$
\gamma_{L V} \cos \theta_{\mathrm{S}}=\gamma_{S V}-\gamma_{S L}
$$

where $\gamma_{L V}, \gamma_{S V}$, and $\gamma_{S L}$ are the liquid-vapor, solid-vapor, and solid-liquid surface free energies, respectively. Using a contact angle measurement system (Phoenix10, SEO Co.), we measured contact angles of deionized water droplets over SAMs at room temperature. The droplet volumes for static and dynamic contact angle measurement were $\sim 1.3 \mu \mathrm{L}$ and $\sim 20-30$ $\mu \mathrm{L}$, respectively.

The dynamic contact angle $(\Delta \cos \theta$, which corresponds to the contact angel hysteresis, the difference between advancing $\left(\cos \theta_{\mathrm{a}}\right)$ and receding $\left.\left(\cos \theta_{\mathrm{r}}\right)\right)$ measurements permit access to degree of structural defects. If the measured value of $\Delta \cos \theta$ is higher than the values of the pure SAMs, the surface becomes disordered and rough; in contrast, if the measured value is lower, it indicates that the surface is relatively ordered (Figure S6). ${ }^{6}$ 


\subsection{X-ray Photoelectron Spectroscopy (XPS) Analysis}

The XPS measurements were carried out on a Thetaprobe (Thermo) with a monochromated $\mathrm{Al} \mathrm{Ka}(1486.6 \mathrm{eV})$ source. The measurements were done at room temperature in a vacuum of $6.7 \times 10^{-8} \mathrm{~Pa}$. The binding energies were calibrated by setting $\mathrm{Ag} 3 \mathrm{~d}_{5 / 2}$ of bulk metals to values $368.26 \mathrm{eV}$ and $\mathrm{Au} 4 \mathrm{f}_{7 / 2}$ of bulk metals to values $84.0 \mathrm{eV}$. $^{7}$ The XPS N1s and S2p lines were detected to study the imSAMs. The peak shapes of the core level photoelectron spectra were analyzed with a XPS Peak Fit program. A Shirley-type background correction was utilized. The $S 2 p_{3 / 2}$ and $S 2 p_{1 / 2}$ lines were fitted with a fixed binding energy difference of $1.18 \mathrm{eV}$ and an intensity ratio of $2: 1$, reflecting the multiplicity of the $S 2 \mathrm{p}_{3 / 2}$ and $\mathrm{S} 2 \mathrm{p}_{1 / 2}$ energy levels. The reproducibility of the data was confirmed by measuring the data from different samples. Since the addition of $\mathrm{SC}_{11} \mathrm{BIPY}$ essentially produced a detectable nitrogen signal in the SAMs, we estimated the values of $\chi_{S C 11 B I P Y}^{\text {surf }}$ by comparing the N1s peak areas for different pure and mixed SAMs, as previously described. ${ }^{6,8}$ We avoided the use of C1s and S2p signals as references to eliminate complexities arising from the surface contamination of SAMs by adventitious airborne organic compounds and the different degrees of sulfur photoelectron attenuation by the alkyl backbones. ${ }^{8,9}$

\subsection{Percent Electrochemically Active Surface Area (\%EAS) Analysis}

The \%EAS measurement is an established wet-electrochemical method, which enables comparison of degree of structural disorder among SAMs. ${ }^{10}$ The \%EAS method typically uses $\mathrm{Ru}^{3+}$ complex (e.g., $\mathrm{Ru}\left(\mathrm{NH}_{3}\right)_{6}$ ) as an electrochemical probe for several reasons: some of these include that it easily undergoes a reversible, one-electron electrochemical reaction, and SAMs remain stable throughout the electrochemical window in which the redox chemistry of the $\mathrm{Ru}^{3+}$ complex occurs. What one measures in the \%EAS experiment is tunneling current across a 
SAM: when negative voltage $(-V)$ is applied to a SAM-based electrochemical cell, current flows from a working electrode (Au in our system) to an electrolyte where a redox probe is reduced $\left(\mathrm{Ru}^{3+} \rightarrow \mathrm{Rh}^{2+}\right)$. If the $\mathrm{SAM}$ is well-packed and structurally ordered, low current flows across the SAM resulting in low cathodic peak current $\left(i_{\mathrm{pc}}\right)$. However, when the SAM is structurally disordered, high current flows across the SAM (and pinholes inside it) resulting in high cathodic current.

\subsection{Reductive Desorption Analysis}

Reductive desorption method enables one to measure packing densities of thiolatebased monolayers. ${ }^{11,12}$ To ensure the same surface area of the SAM exposed to the electrolyte solution across different samples, we used a custom built three-electrode setup (composed of Teflon) equipped with a platinum wire counter electrode, a $\mathrm{Ag} / \mathrm{AgCl} / \mathrm{KCl}$ reference electrode, and a screw cap to hold the working electrode (area exposed to the solution $=0.152 \mathrm{~cm}^{2}$ ). First, we removed oxygen dissolved in $0.5 \mathrm{M} \mathrm{KOH}$ aqueous solution through nitrogen gas bubbling. We carried out measurements by sweeping voltage from $-0.20 \mathrm{~V}$ to $-1.40 \mathrm{~V}$ at room temperature. Scan rate was $100 \mathrm{mV} / \mathrm{s}$. In a typical experiment, a linear voltage sweep was applied from a potential at which the electrode was covered by a thiolate monolayer to a negative potential at which the thiolate was desorbed from the surface, and a voltammetric curve was recorded. Integration of voltammetric curve gave the charge corresponding to the desorption $(Q)$. Assuming that the desorption took place through the reduction of $\mathrm{Au}(\mathrm{I})$ to $\mathrm{Au}(0)$ according to the reaction, $\mathrm{AuSR}+\mathrm{e}^{-} \rightarrow \mathrm{Au}(0)+\mathrm{RS}^{-}$, the surface coverage $\Gamma$ was calculated with the equation, $\Gamma=Q / n F A$. Here, $F$ is the Faraday constant, $A$ is the exposed area, and $n$ is the number of electrons used for reductive reaction (here, $n=1$ ). 


\subsection{Electrochemical Impedance Spectroscopy (EIS) Analysis}

Electrochemical impedance spectroscopy (EIS) measurements were obtained in a conventional three electrode electrochemical cell using a potentiostat (VersaSTAT 3, Princeton Applied Research). The counter and reference electrodes were a platinum mesh and a $\mathrm{Ag} / \mathrm{AgCl}$ electrode $(3 \mathrm{M} \mathrm{NaCl})$, respectively. By using a custom-built equipment, the measurement area $\left(0.15 \mathrm{~cm}^{2}\right)$ of SAM was kept identical across all samples. The impedance spectra at an applied potential of $0 \mathrm{~V}$ (vs $\mathrm{Ag} / \mathrm{AgCl})$ in $\mathrm{K}_{2} \mathrm{HPO}_{4}(30 \mathrm{mM}$, $\mathrm{pH}$ 7.7-8.7).

The effect of ReSEM on SAM permeability was investigated over a frequency range from $1 \mathrm{~Hz}$ to $10 \mathrm{kHz}$ by applying a sinusoidal signal of $\pm 10 \mathrm{mV}$ against open circuit voltage. Each measurement comprised one frequency scan, and two measurements were taken per sample at intervals of $20 \mathrm{~min}$. The impedance spectra were analyzed by fitting appropriate equivalent circuit models to the measured data (VersaStudio).

\subsection{Atomic Force Microscopy (AFM) Analysis}

Topographical morphology of bottom electrodes was measured by atomic force microscopy (Multimode 8, Bruker) in ambient condition. AFM tips (SNL-10) with a resonant frequency of $65 \mathrm{kHz}$ and spring constant of $0.350 \mathrm{~N} / \mathrm{m}$ were used in the topography measurements. During the scan, a set point was $1 \mathrm{~V}$ and scan rate was $1.32 \mathrm{~Hz}$.

\subsection{Ellipsometry Analysis}

We measured the thickness for pure $\mathrm{SC}_{11} \mathrm{BIPY} \mathrm{SAM}$ and $\mathrm{imSAM}^{2 \mathrm{nd}}$ formed with $\mathrm{HSC}_{11} \mathrm{BIPY}$ and $\mathrm{HSC}_{8}$ on $\mathrm{Au}^{\mathrm{TS}}$ using ellipsometry. The data were obtained at a constant incidence angle of $70^{\circ}$ using a single-wavelength scanning ellipsometer (alpha-SE ${ }^{\circledR}$ model, J.A. Woollam). The thickness of the SAM was calculated using CompleteEASE® software. 


\subsection{Near Edge X-ray Adsorption Fine Structure Spectroscopy (NEXAFS) Analysis}

Near edge X-ray adsorption fine structure (NEXAFS) spectroscopy measurements were performed at 4D PES beam line of Pohang Accelerator Laboratory (PAL) in South Korea. We used the partial electron yield (PEY) detection mode for the NEXAFS spectra by recording the sample current normalized to a signal current, which was measured simultaneously using a gold mesh in ultrahigh vacuum $\left(<10^{-9}\right.$ Torr $)$. In this case, a $p$ polarized ( 85\%) synchrotron photon beam had an energy in the range of $270-325 \mathrm{eV}$ and spectral energy resolution of $\Delta E=150 \mathrm{meV}$. Carbon K-edge angle-dependent NEXAFS from $30^{\circ}$ to $70^{\circ}$ is sensitive to the $\pi^{*}$ antibonding orbital along the $\pi$ bond (Figure S15). The NEXAFS spectra of typical $\pi$-conjugated organic semiconductors shows a $\mathrm{C} 1 \mathrm{~s}$ to $\pi^{*}$ resonance at $284-287 \mathrm{eV}$. The average molecular orientation was determined by analyzing the change in the intensity of the $\pi^{*}(\mathrm{C}=\mathrm{C})$ and $\sigma^{*}(\mathrm{C}-\mathrm{C})$ resonance value at 284.5 and 293.0 $\mathrm{eV}$, respectively, as the angle of incidence of the X-ray beam was changed. The peak intensities of the $\pi^{*}(\mathrm{C}=\mathrm{C})$ and $\sigma^{*}(\mathrm{C}-\mathrm{C})$ orbital in the NEXAFS spectra were then fitted by the following Eq. S2:

$$
\mathrm{I}_{v}=\left[\frac{P}{3}\left\{1+\frac{1}{2}\left(3 \cos ^{2} \theta-1\right)\left(3 \cos ^{2} \alpha-1\right)\right\}+\frac{(1-P)}{2} \sin ^{2} \alpha\right] \quad \text { Eq. } \mathrm{S} 2
$$

where $\theta$ was the polarization angle of the incident synchrotron light with respect to the normal to the surface, and $P=0.85$ was used for the degree of polarization. By simply evaluating the intensity ratio at various angles from normal incidence $\left(\theta=70^{\circ}\right)$ to grazing incidence $\left(\theta=30^{\circ}\right)$, the tilt angle of alkyl backbone could be derived. 


\section{Molecular Dynamics (MD)}

\subsection{Molecular Dynamics Simulation Setup}

In this study, we have performed atomistic molecular dynamic (MD) simulations of two different $\mathrm{SAM}$ systems consisting of $\mathrm{SC}_{11} \mathrm{BIPY}+\mathrm{SC}_{8}$. The two surfactant molecules $\left(\mathrm{SC}_{11} \mathrm{BIPY}\right.$ and $\left.\mathrm{SC}_{8}\right)$ are modelled using CHARMM General Force Fields (CGenFF). ${ }^{13}$ Each SAM system consists of total 100 surfactant molecules with different molecule fractions, $\chi_{S C 11 B I P Y}^{\text {surf }}$, of $\mathrm{SC}_{11} \mathrm{BIPY}$, ranging from 0 to $100 \%$. The interaction between the surfactant molecule and the solid metallic surface is not explicitly present in this study. Instead, the thiol group $(-\mathrm{SH})$ is replaced by the sulfide anion $\left(-\mathrm{S}^{-}\right)$to mimic the metal-sulfide bond and the following plane harmonic restraint, $U_{\text {res }}$, with the force constant, $k$, of $1000 \mathrm{kcal} / \mathrm{mol} \cdot \AA^{2}$ is applied to all sulfur atoms so that they can move freely on a planar surface but not in the normal direction to the surface: $U_{\text {res }}(z)=\left\{\begin{array}{r}0, z \geq z_{0} \\ \frac{1}{2} k\left(z-z_{0}\right)^{2}, z<z_{0}\end{array}\right.$, where $z$ is the position of each sulfur atom in the direction normal to the surface and $z_{0}$ is set to $10 \AA . \mathrm{Na}^{+}$ions are also added to make the system neutral. Additional plane harmonic restraint with the force constant of $400 \mathrm{kcal} / \mathrm{mol} \cdot \AA^{2}$ are also applied to the other atoms so that they cannot penetrate into the planar surface. This treatment has been successfully applied to the prediction for the surface coverage of various SAM systems in the previous study. ${ }^{14}$

All MD simulations are carried by CHARMM software package (c38b2 version). ${ }^{15}$ Each simulation box consists two SAM systems, which are aligned in the opposite direction and separated by $20 \AA$, which enables us to simulate two SAM systems at the same time. The representative snapshot is shown in Figure 4a. Each initial simulation box is set to $5.0 \times 5.0$ $\times 20.0 \mathrm{~nm}^{3}$ and the periodic boundary condition is applied to all directions. The equilibrium 
MD simulation is then performed in the constant $\mathrm{NP}_{t} \mathrm{~L}_{z} T$ ensemble for $100 \mathrm{~ns}$, where $N, \mathrm{P}_{t}, \mathrm{~L}_{z}$, and $\mathrm{T}$ are respectively the number of surfactant molecules, the lateral pressure in the direction parallel to the solid surface, the box length in the direction normal to the surface, and the system temperature. $\mathrm{P}_{\mathrm{t}}$ is set to $1 \mathrm{~atm}$ using Langevin piston pressure method and T to $298 \mathrm{~K}$ using Nose-Hoover thermostat. ${ }^{16,17}$ The first 10 trajectories are discarded for equilibration and the last $90 \mathrm{~ns}$ trajectories are used for the calculation of the structural and thermodynamic properties of SAM such as surface coverage, tilt angle, and energy decomposition. The error bars are obtained from the block average of the equilibrated trajectories.

\subsection{Surface Coverage Calculation}

Figure S11 shows the simulated surface coverage, $\Gamma$, of the two SAM systems as a function of the mole fraction, $\chi_{S C 11 B I P Y}^{\text {surf }}$. As $\chi_{S C 11 B I P Y}^{\text {surf }}$ decreases, $\Gamma$ increases for $\operatorname{imSAM}^{2 \text { nd }}$. The $\Gamma$ starts leveling off at $\chi_{S C 11 B I P Y}^{\text {surf }}<0.6$, which means that the replacement of $\mathrm{SC}_{11} \mathrm{BIPY}$ by $\mathrm{SC}_{8}$ does not affect $\Gamma$ very much at low $\chi_{S C 11 B I P Y}^{\text {surf }}$. This can be understood by the fact that the BIPY group of $\mathrm{SC}_{11} \mathrm{BIPY}$ is located high enough not to disturb the packing of both $\mathrm{SC}_{8}$ and the $\mathrm{SC}_{11}$ moiety of $\mathrm{SC}_{11} \mathrm{BIPY}$. In the case of the $\Gamma$ derived by experiment, the experimentally determined (by XPS) values of $\chi_{S C 11 B I P Y}^{\operatorname{surf}}$ for one and two ReSEM cycles were nearly the same, but the $\Gamma$ significantly increased (by 1.5 times). This finding supports that the $\mathrm{SC}_{8}$ was adsorbed between the $\mathrm{SC}_{11} \mathrm{BIPY}$ in the interstitial fashion.

\subsection{Tilt Angle Calculation}

We calculated two types of tilt angles of $\mathrm{SC}_{11} \mathrm{BIPY}$ : one is the tilt angle, $\theta_{t}$, of the hydrocarbon backbone relative to the surface normal (Figure S13a), and the other is the tilt angle, $\theta_{p z}$, of the BIPY plane relative to the surface normal (Figure S13b). The $\theta_{t}$ steeply 
decreased between $\chi_{S C 11 B I P Y}^{\operatorname{surf}}=1.0$ and 0.6. At low $\chi_{S C 11 B I P Y}^{\text {surf }}<0.6$, the hydrocarbon backbone of $\mathrm{SC}_{11} \mathrm{BIPY}$ gradually decreased. This means that the degree of vertical orientation of the alkyl backbone increased the most at $\chi_{S C 11 B I P Y}^{\operatorname{surf}}=0.6$. As shown in Figure S14, the distribution of $\theta_{\mathrm{pz}}$ was bimodal: upright (low $\theta_{p z}$ ) and bowed (high $\theta_{p z}$ ) conformations. As $\chi_{S C 11 B I P Y}^{\text {surf }}$ was lowered, the portion of the bowed conformation became larger and therefore the average $\theta_{p z}$ decreased. On the other hand, $\theta_{p z}$ was mono-modal, which corresponded to the upright conformation.

\subsection{Decomposition of Intermolecular Energy between Single SC11BIPY and}

\section{Surrounding Surfactant Molecules}

We also decomposed the intermolecular energy between single $\mathrm{SC}_{11} \mathrm{BIPY}$ and surrounding surfactant molecules into three parts: BIPY-BIPY, BIPY-tail (tail: $\mathrm{SC}_{11}$ in $\mathrm{SC}_{11} \mathrm{BIPY}$ and $\mathrm{SC}_{8}$ ), and tail-tail, as shown in Figure $4 \mathrm{~d}$. As $\chi_{S C 11 B I P Y}^{\text {surf }}$ was reduced, $\mathrm{E}_{\mathrm{BIPY}-\mathrm{BIPY}}$ was destabilized in mixed SAM systems because the number of surrounding BIPY groups

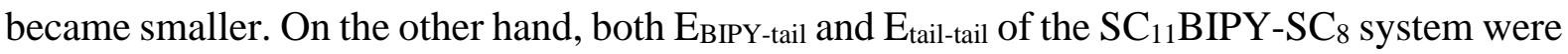
not strongly affected by $\chi_{S C 11 B I P Y}^{\text {surf }}$. It should be noted that the system with $\chi_{S C 11 B I P Y}^{\text {surf }}=0.6$ was the most stable, in agreement with the experiment results. 


\section{$\underline{\text { 5. Minor Discussion }}$}

\section{Reductive Desorption Analysis on ReSEM-based Mixed SAMs}

Figure S8 shows cyclic voltammograms (CVs) obtained from reductive desorption experiments with ReSEM-based mixed SAMs formed on $\mathrm{Au}^{\mathrm{TS}}$. Data shows one main desorption peak and one shoulder peak at $-1.0--1.2 \mathrm{~V}$ and $-1.3 \mathrm{~V}$, respectively. The shoulder peaks were attributed to reductive desorption from different domains on the polycrystalline gold electrode. The polycrystalline gold can have low-index faces $\mathrm{Au}(111), \mathrm{Au}(100)$ and $\mathrm{Au}(110)$ as well as $\mathrm{Au}(210)$. Depending on the crystallographic orientation of gold surface, the interaction and binding site between gold and sulfur can vary to some extent. ${ }^{18}$ The fine shoulder peak (-1.3 V) in our CVs could be attributed to the desorption at Au (210). Steichen at el. ${ }^{19}$ have previously observed the desorption peak at $-1.3 \mathrm{~V}$ in $n$-decanethiolate SAM formed on polycrystalline gold electrode. 


\section{Supplementary Figures and Tables}
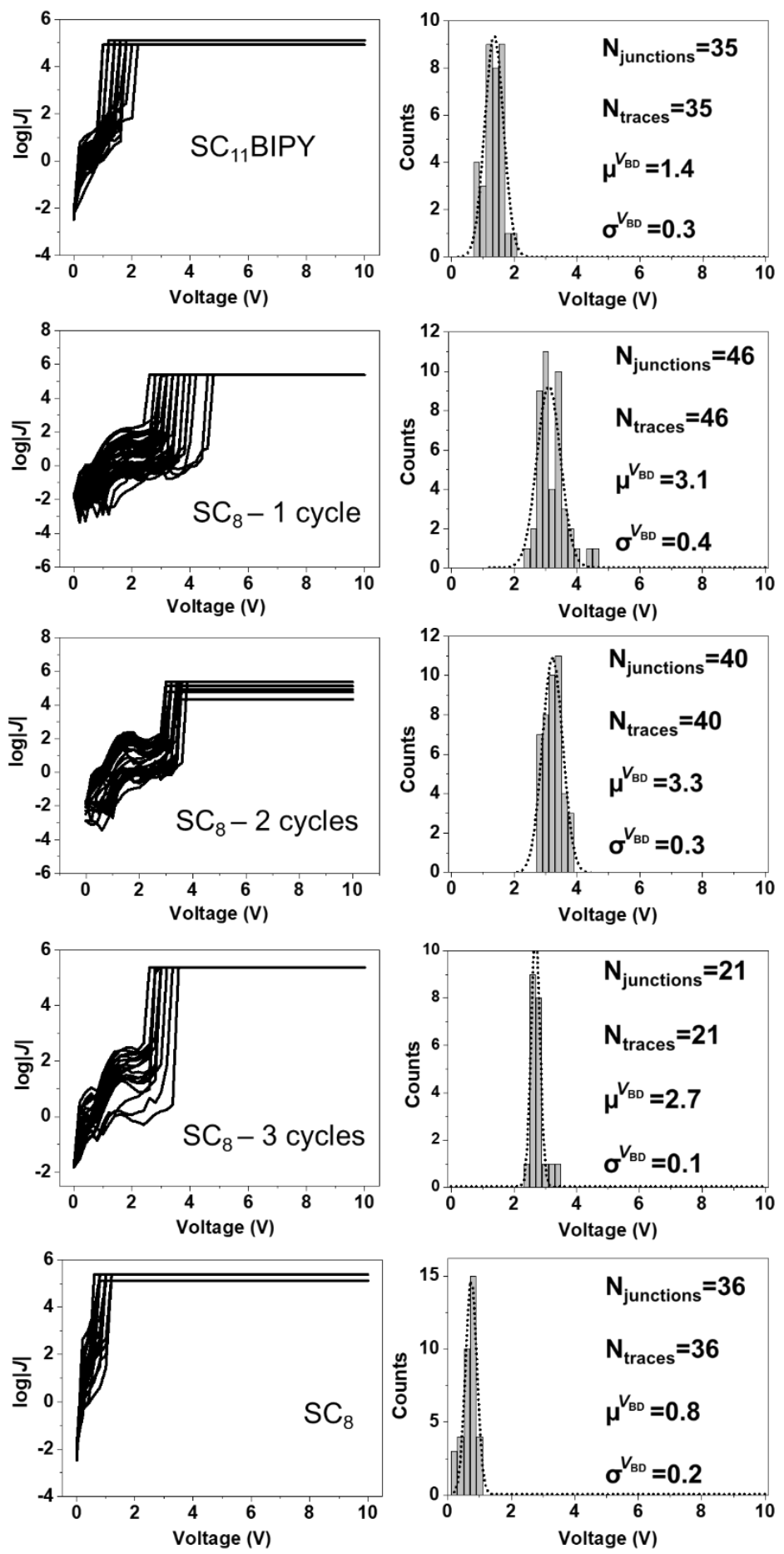

Figure S1. $J(V)$ traces and histograms of breakdown voltage $\left(V_{\mathrm{BD}}\right)$ for pure $\mathrm{SC}_{11} \mathrm{BIPY}$ and $\mathrm{SC}_{8}$ SAMs and a series of mixed SAMs formed with $\mathrm{HSC}_{11} \mathrm{BIPY}$ and $\mathrm{HSC}_{8}$ on $\mathrm{Au}^{\mathrm{TS}}$ via different numbers of ReSEM cycles. 

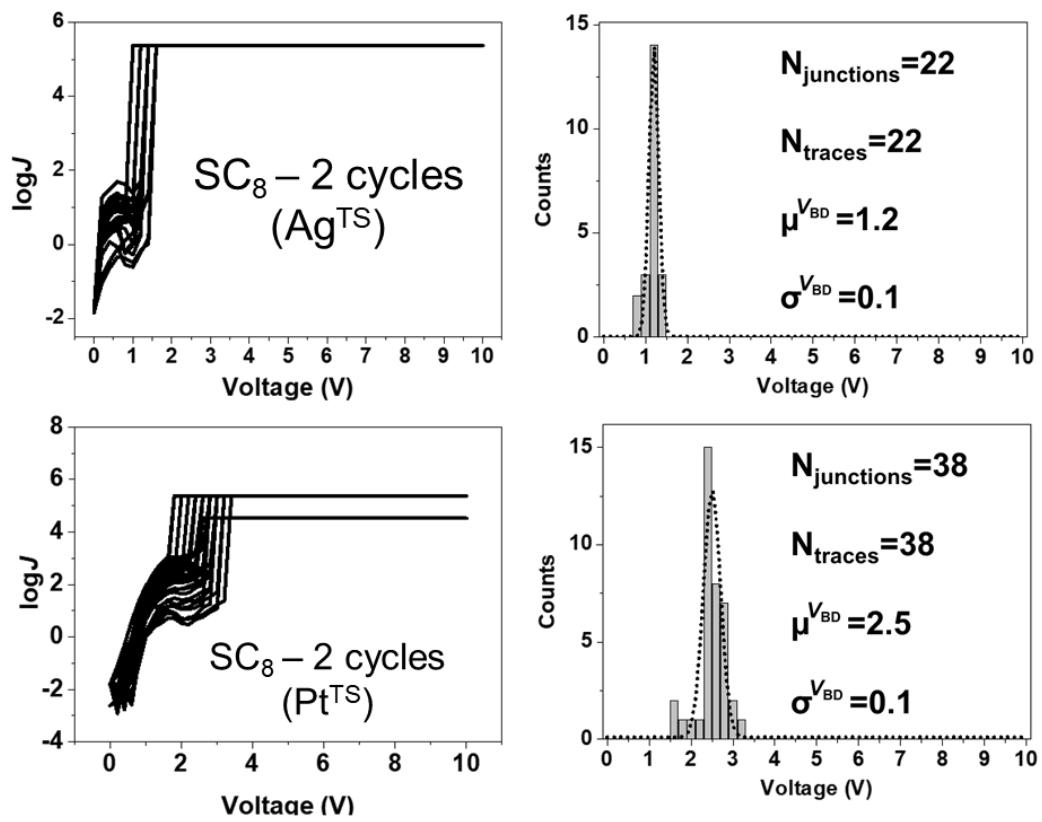

Figure S2. $J(V)$ traces and histograms of breakdown voltage $\left(V_{\mathrm{BD}}\right)$ for mixed SAMs formed with $\mathrm{SC}_{11} \mathrm{BIPY}$ and $\mathrm{SC}_{8}$ on $\mathrm{Ag}^{\mathrm{TS}}$ and $\mathrm{Pt}^{\mathrm{TS}}$ via two ReSEM cycles. 

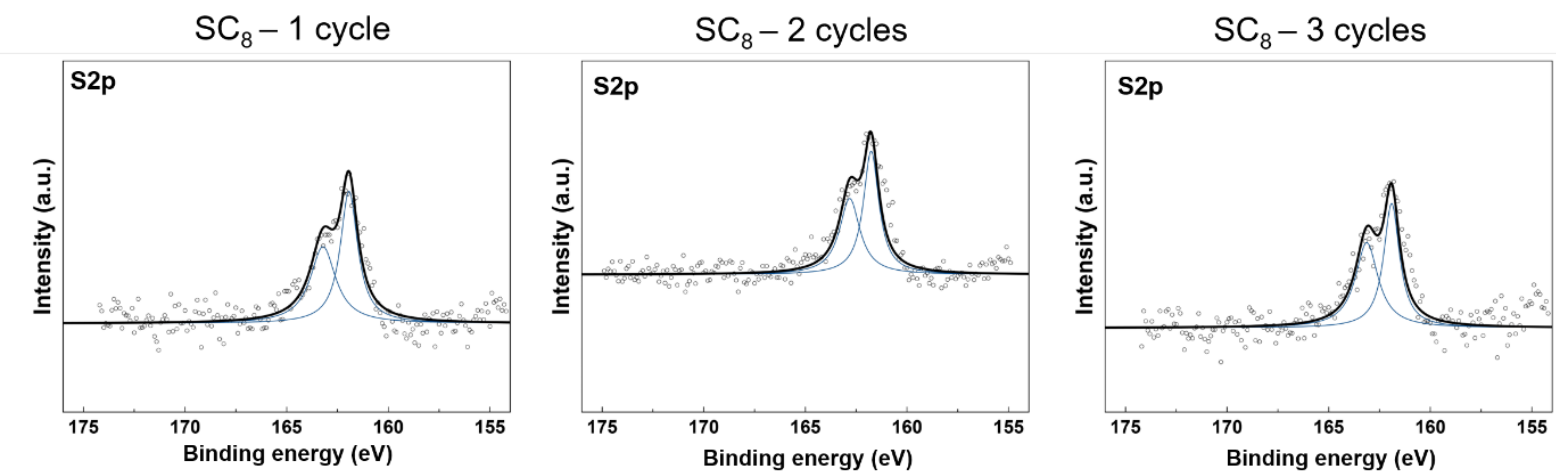

Figure S3. High resolution S2p X-ray photoelectron spectra for a series of mixed SAMs formed with $\mathrm{HSC}_{11} \mathrm{BIPY}$ and $\mathrm{HSC}_{8}$ on $\mathrm{Au}^{\mathrm{TS}}$ via different numbers of ReSEM cycles. All the spectra show single type of spin-orbit coupled doublets ( 162 and $\sim 163 \mathrm{eV}$ for $2 \mathrm{p}_{3 / 2}$ and $2 \mathrm{p}_{1 / 2}$, respectively), indicative of chemisorbed sulfur. 


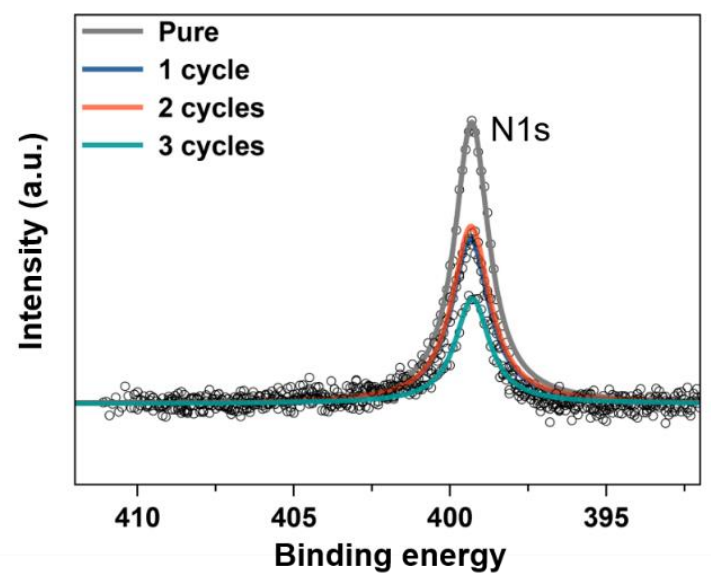

Figure S4. High resolution N1s X-ray photoelectron spectra for a series of mixed SAMs formed with $\mathrm{HSC}_{11} \mathrm{BIPY}$ and $\mathrm{HSC}_{8}$ on $\mathrm{Au}^{\mathrm{TS}}$ via different numbers of ReSEM cycles. 


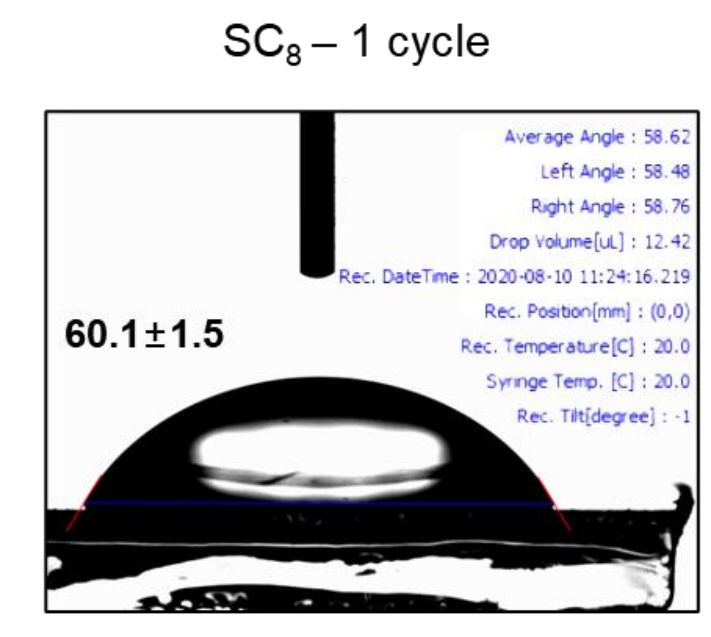

$\mathrm{SC}_{8}-2$ cycles

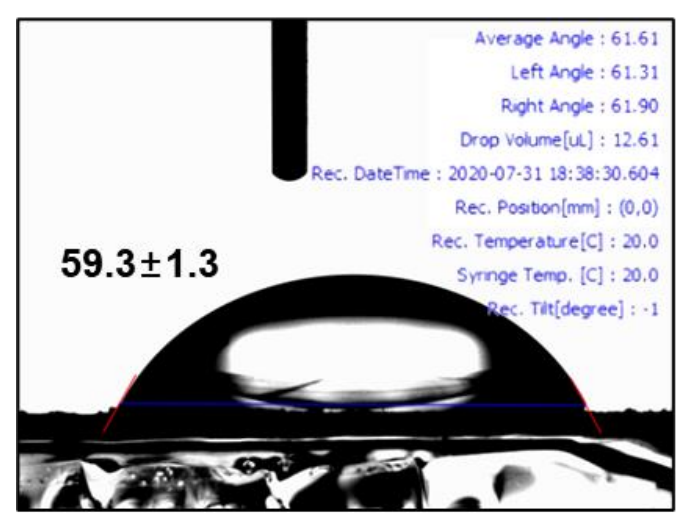

$$
\mathrm{SC}_{8}-3 \text { cycles }
$$

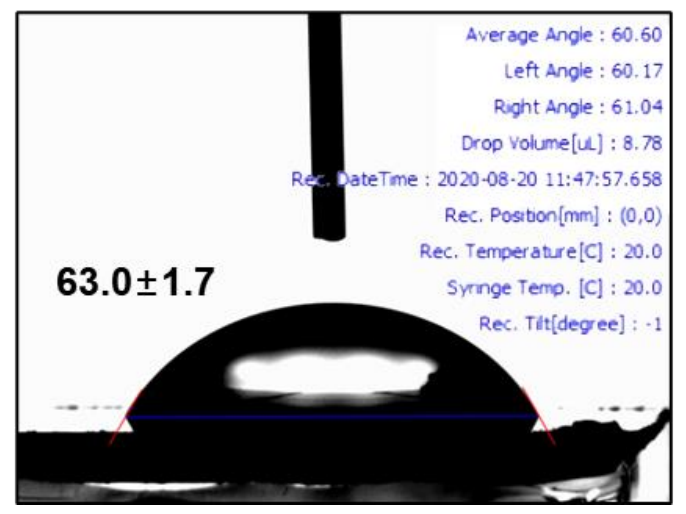

Figure S5. Measurements of static water contact angle for a series of mixed SAMs formed with $\mathrm{HSC}_{11} \mathrm{BIPY}$ and $\mathrm{HSC}_{8}$ on $\mathrm{Au}^{\mathrm{TS}}$ via different numbers of ReSEM cycles. Data were averaged from eight separate measurements. 


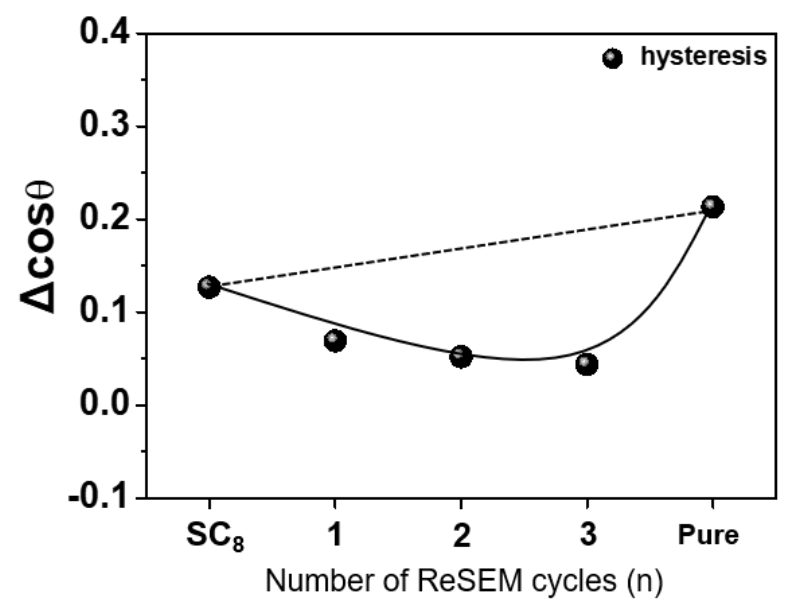

Figure S6. Plots of dynamic water contact angle $(\Delta \cos \theta)$ for a series of mixed SAMs formed with $\mathrm{HSC}_{11} \mathrm{BIPY}$ and $\mathrm{HSC}_{8}$ on $\mathrm{Au}^{\mathrm{TS}}$ via different numbers of ReSEM cycles. 
(a)

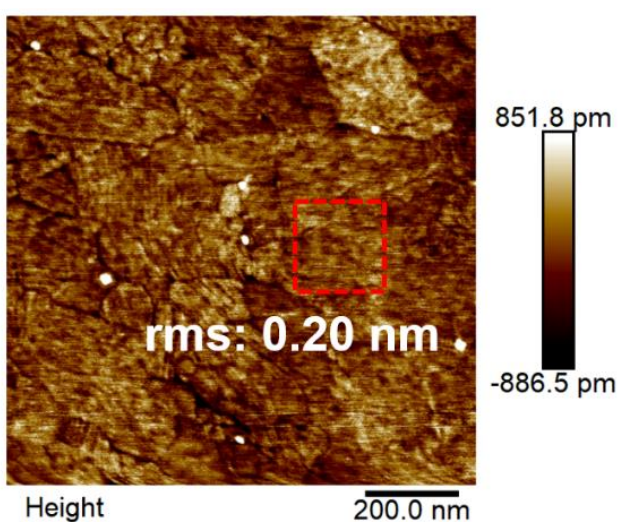

(b)

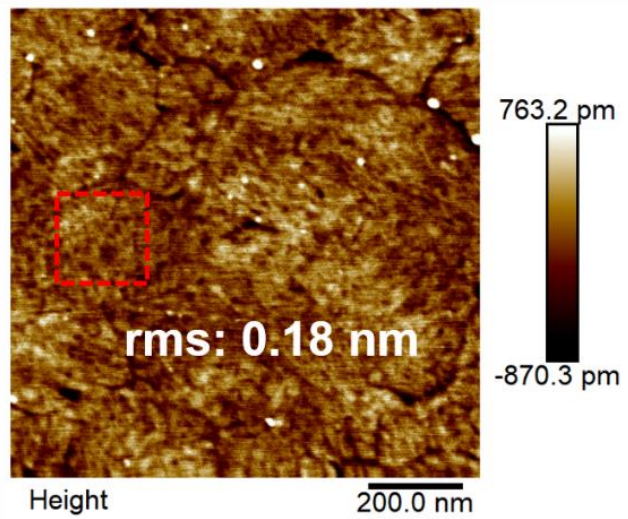

Figure S7. AFM analysis of (a) pure $\mathrm{SC}_{11} \mathrm{BIPY} \mathrm{SAM}$ and (b) imSAM${ }^{2 \mathrm{nd}}$ on $\mathrm{Au}^{\mathrm{TS}}$. 


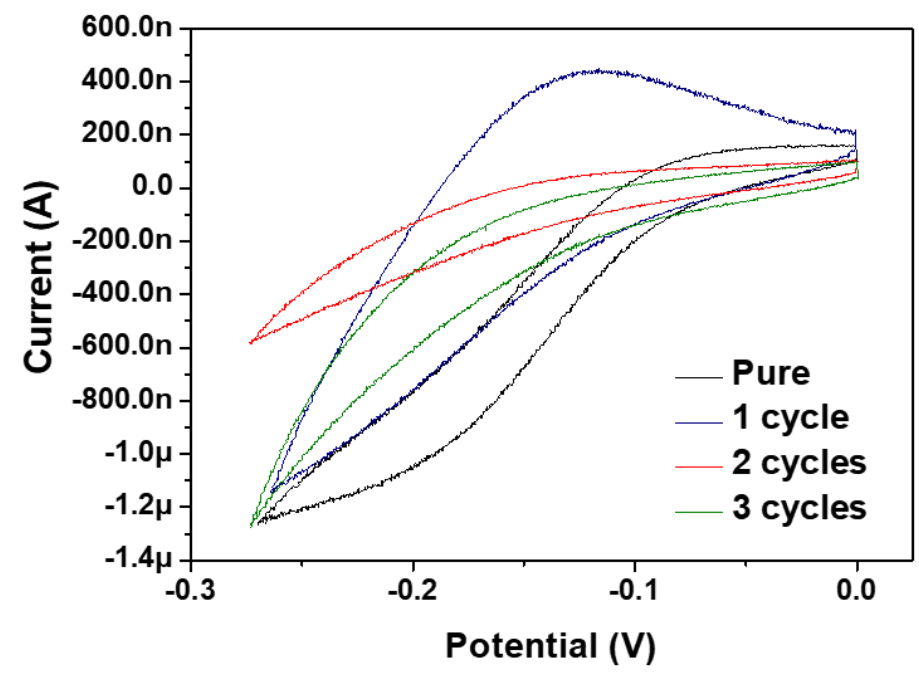

Figure S8. \%EAS analysis for pure $\mathrm{SC}_{11} \mathrm{BIPY}$ SAM and a series of mixed SAMs formed with $\mathrm{HSC}_{11} \mathrm{BIPY}$ and $\mathrm{HSC}_{8}$ on $\mathrm{Au}^{\mathrm{TS}}$ via different numbers of ReSEM cycles. 


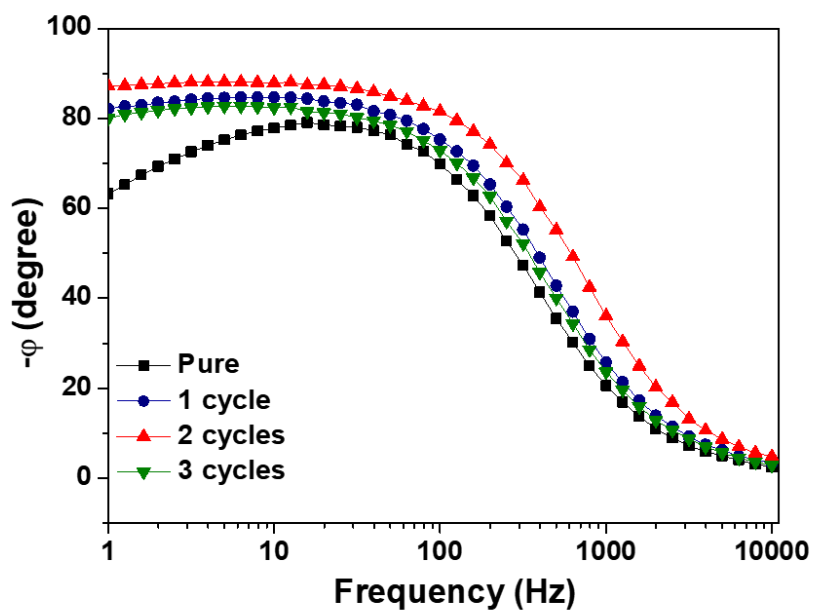

Figure S9. Bode phase plots of pure $\mathrm{SC}_{11} \mathrm{BIPY}$ SAM and mixed SAMs formed with $\mathrm{HSC}_{11} \mathrm{BIPY}$ and $\mathrm{HSC}_{8}$ on $\mathrm{Au}^{\mathrm{TS}}$ via different numbers of ReSEM cycles. The data were averaged from seven separate measurements. 


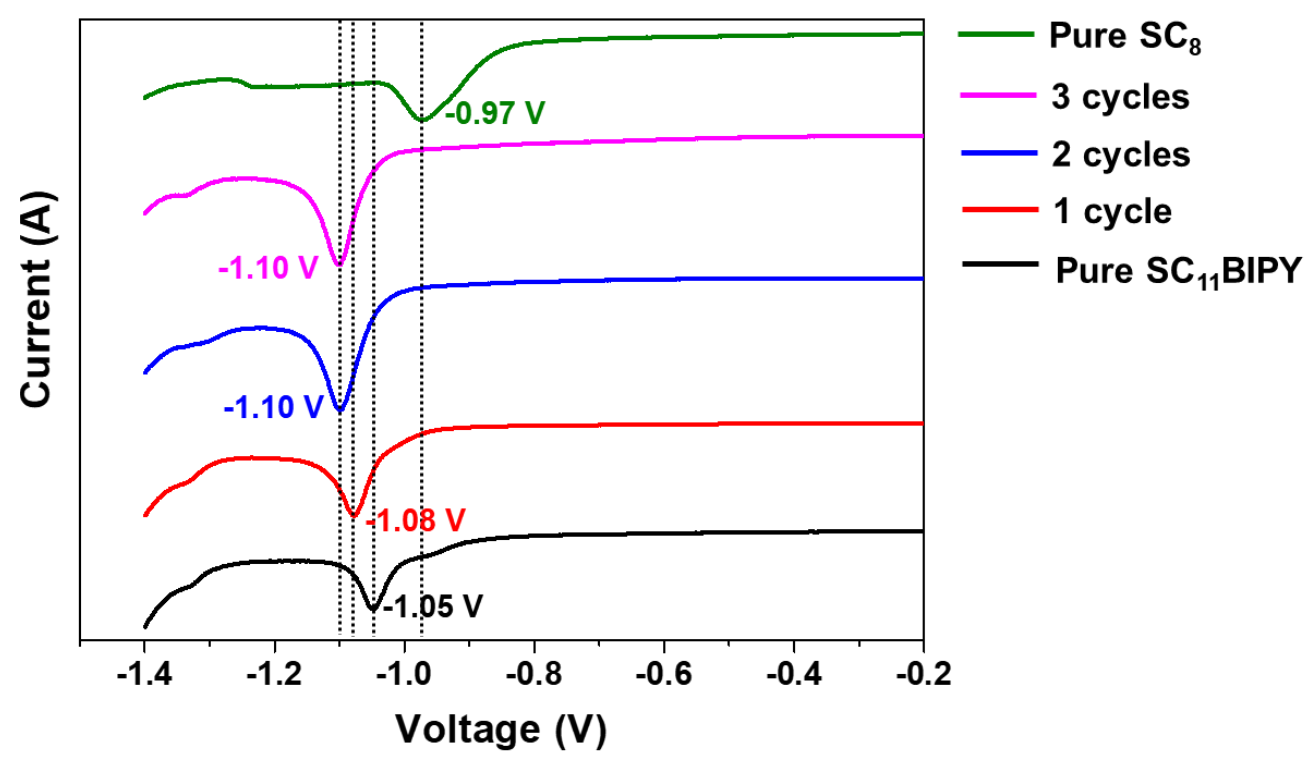

Figure S10. Linear voltammograms for reductive desorption of pure $\mathrm{SC}_{11} \mathrm{BIPY} \mathrm{SAM}$, pure $\mathrm{SC}_{8} \mathrm{SAM}$ and mixed SAMs formed with $\mathrm{HSC}_{11} \mathrm{BIPY}$ and $\mathrm{HSC}_{8}$ on $\mathrm{Au}^{\mathrm{TS}}$ via different numbers of ReSEM cycles. 


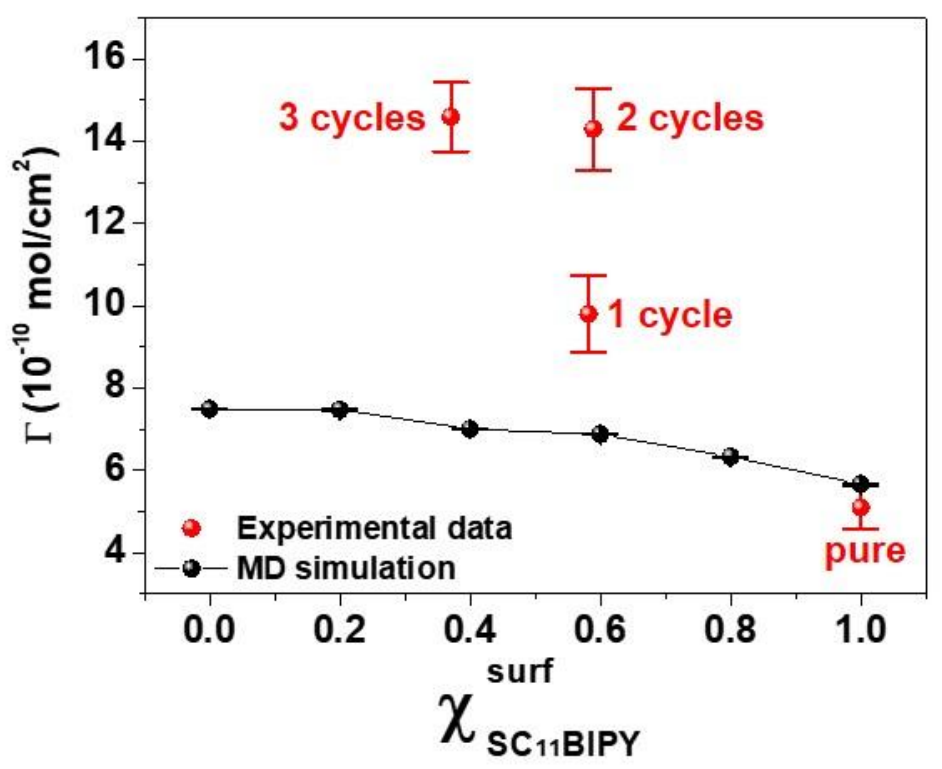

Figure S11. Plots of surface coverage $\left(\Gamma, \mathrm{mol} / \mathrm{cm}^{2}\right)$ determined by experiments and simulations for mixed SAMs formed with $\mathrm{HSC}_{11} \mathrm{BIPY}$ and $\mathrm{HSC}_{8}$ on $\mathrm{Au}$. 


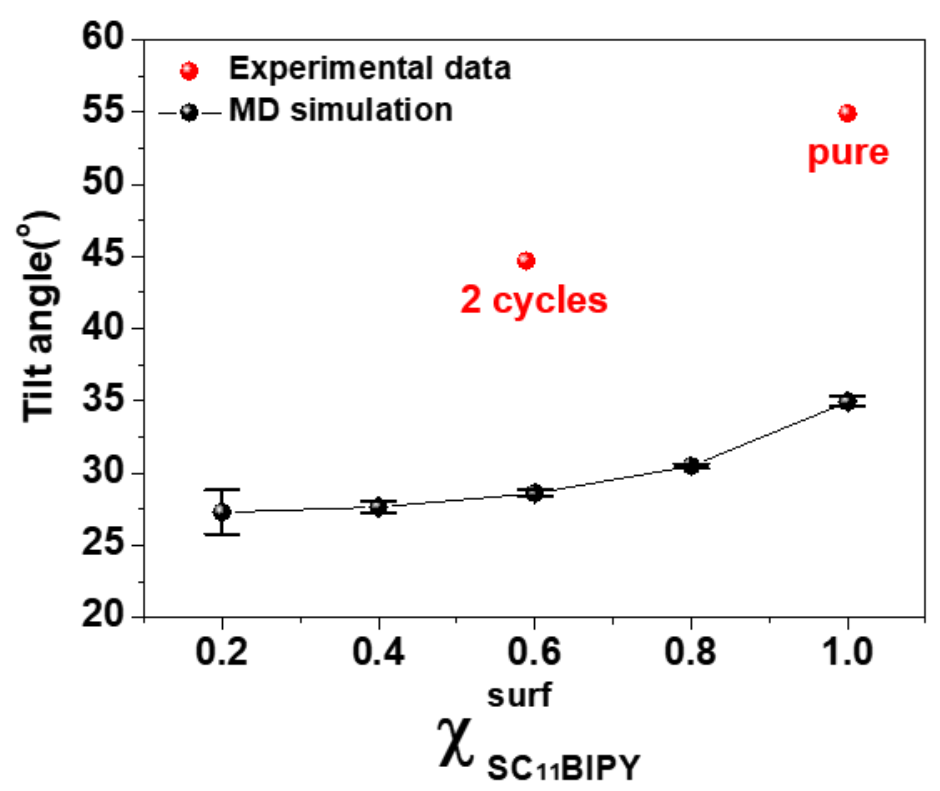

Figure S12. Plots of tilt angle of alkyl backbone determined by experiments (with NEXAFS) and simulations for mixed SAMs formed with $\mathrm{HSC}_{11} \mathrm{BIPY}$ and $\mathrm{HSC}_{8}$ on $\mathrm{Au}$. 
(a)

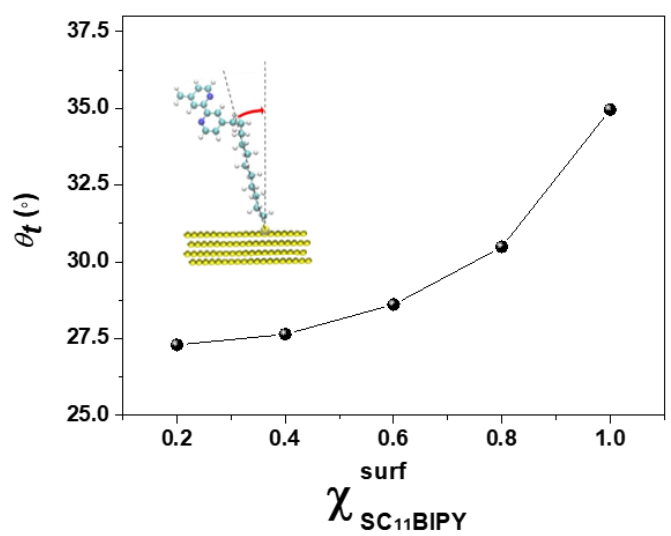

(b)

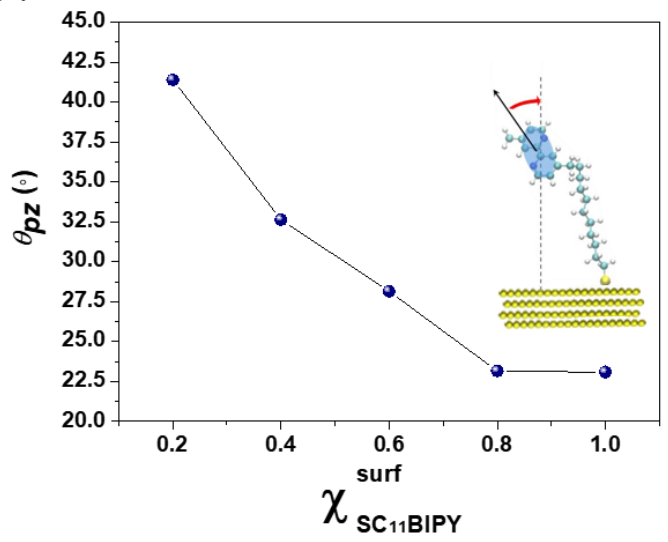

Figure S13. MD-simulated tilt angle, $\theta_{t}$, of the hydrocarbon backbone of $\mathrm{SC}_{11} \mathrm{BIPY}$ and (b) tilt angle, $\theta_{p z}$, of the BIPY plane relative to the surface normal for imSAMs. 
Distribution of tilt angles of BIPY-plane with $\mathrm{SC}_{8}$

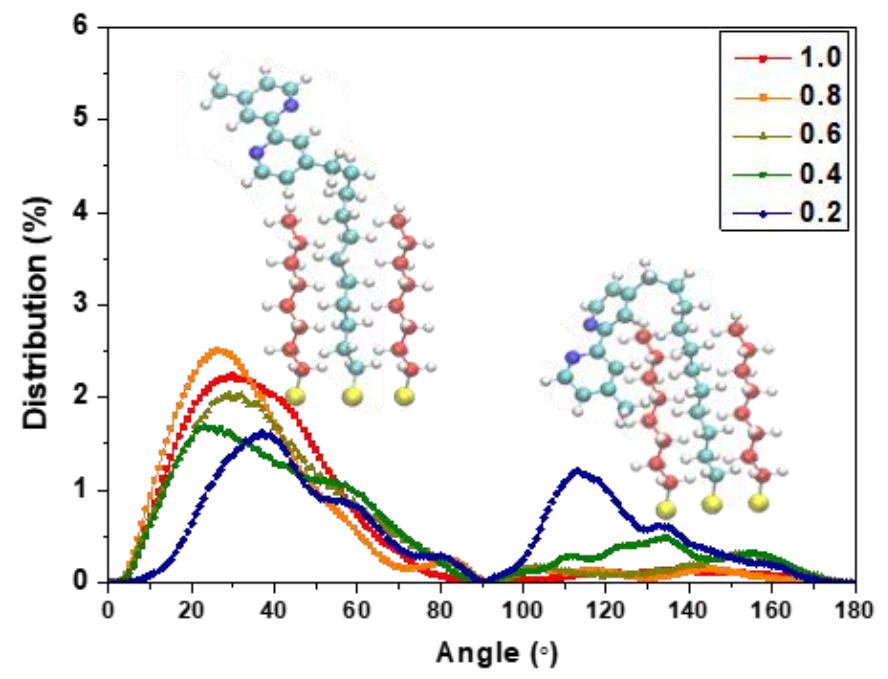

Figure S14. MD simulated distribution of $\theta_{\mathrm{pz}}$ (tilt angles of BIPY-plane with $\mathrm{SC}_{\mathrm{n}}$ ) in the mixed SAMs formed with $\mathrm{HSC}_{11} \mathrm{BIPY}$ and $\mathrm{HSC}_{8}$ for various $\chi_{S C 11 B I P Y}^{\text {surf }}$. Representative snapshots are also shown in the figure. 
(a)

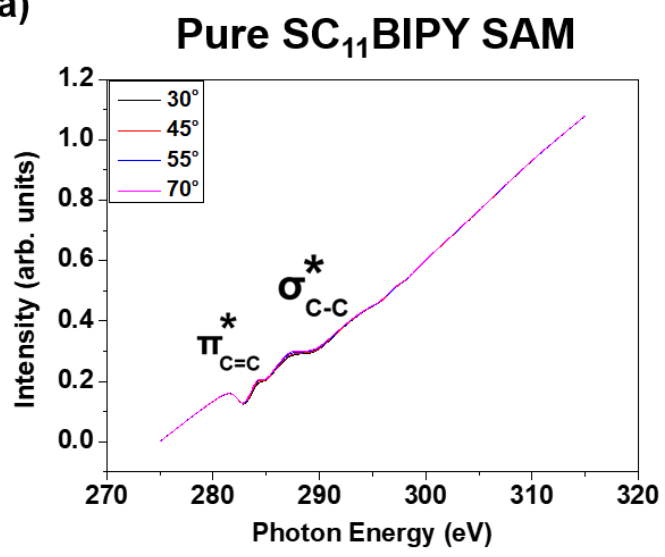

(b)

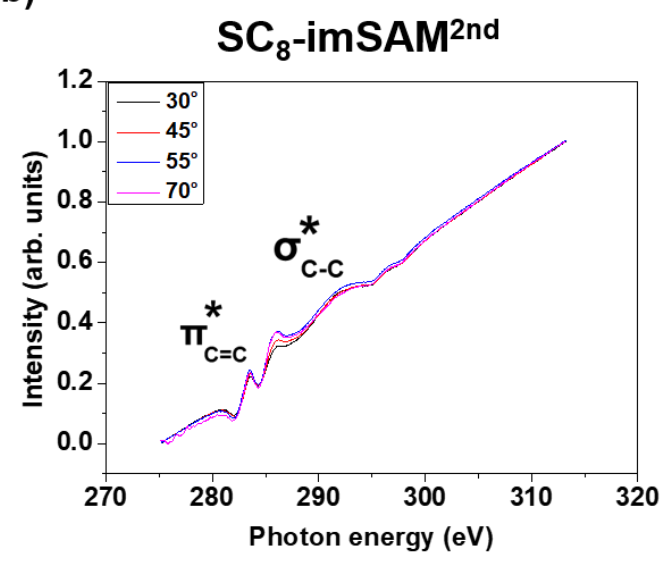

Figure S15. C1s NEXAFS spectra for (a) pure $\mathrm{SC}_{11} \mathrm{BIPY} S A M(b) \mathrm{imSAM}^{2 \text { nd }}$ on $\mathrm{Au}^{\mathrm{TS}}$ at various angles from normal $\left(70^{\circ}\right)$ to grazing $\left(30^{\circ}\right)$ X-ray incidence angles. 

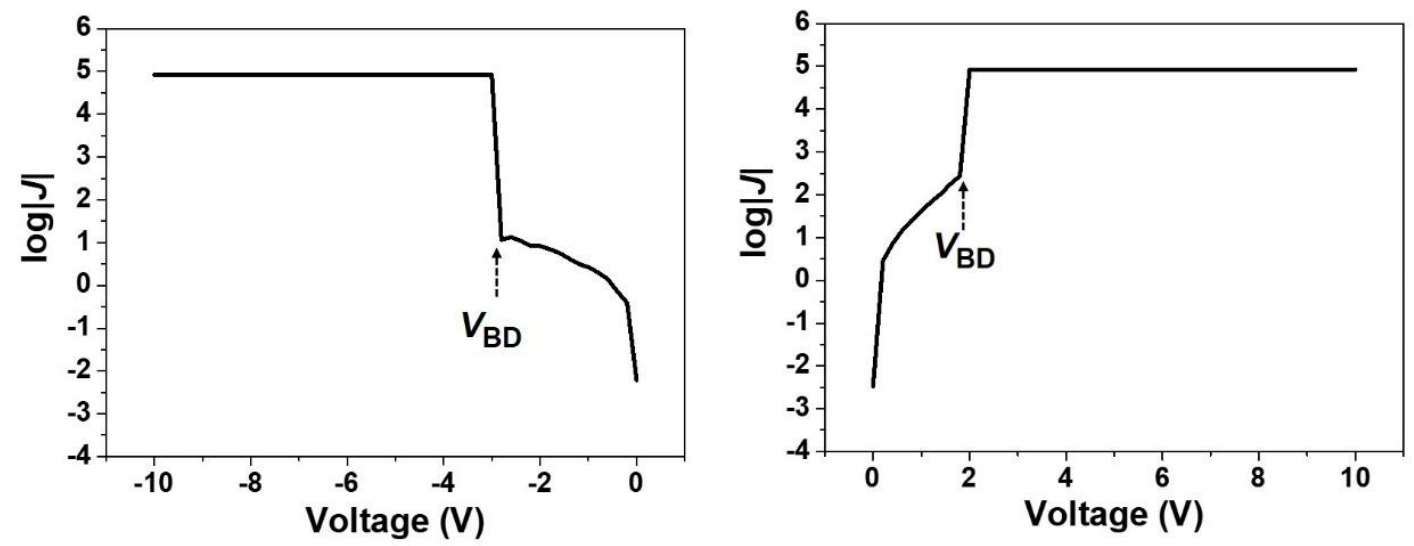

Figure S16. Representative breakdown $J$ - $V$ curves in forward and reverse biases for $\operatorname{imSAM}^{2 \text { nd }}$ SAM. 
(a)
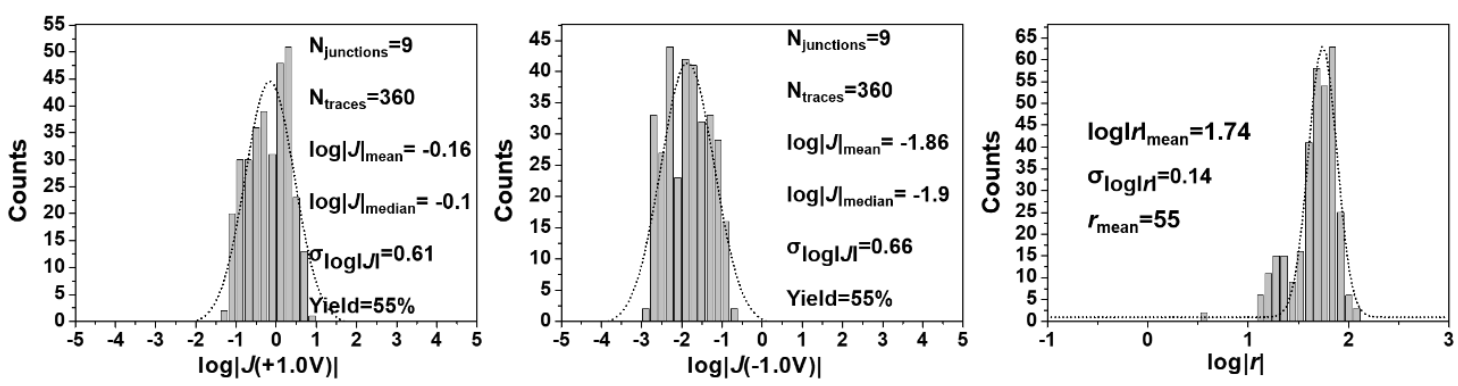

(b)

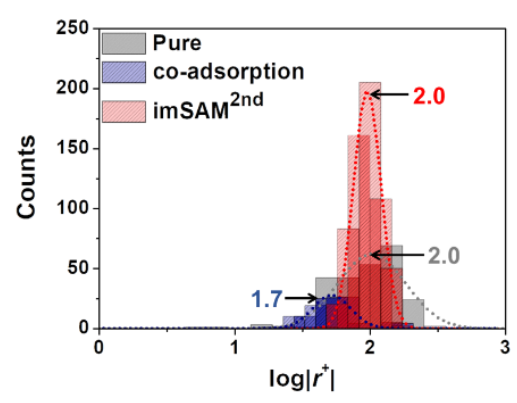

Figure S17. (a) Histograms of $\log |J(V)|$ and $\log |r|$ values for mixed SAM formed with $\mathrm{HSC}_{11} \mathrm{BIPY}$ and $\mathrm{HSC}_{8}$ on $\mathrm{Au}^{\mathrm{TS}}$ via traditional co-adsorption. (b) Histograms of $\log |r|$ value for the pure $\mathrm{SC}_{11} \mathrm{BIPY} \mathrm{SAM}$, mixed SAM formed via traditional co-adsorption, and $\operatorname{imSAM}^{2 \mathrm{nd}}$. 


\section{$1.0 \mathrm{~V}$}
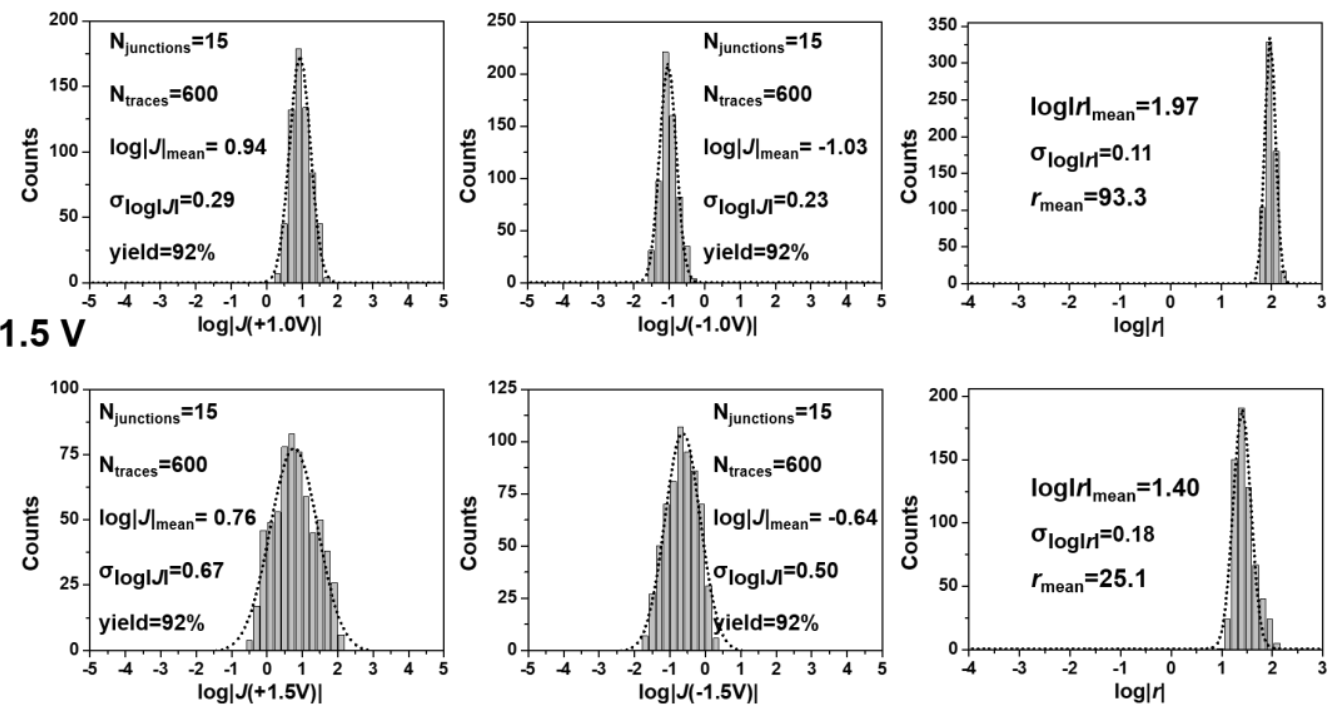

\section{$2.0 \mathrm{~V}$}
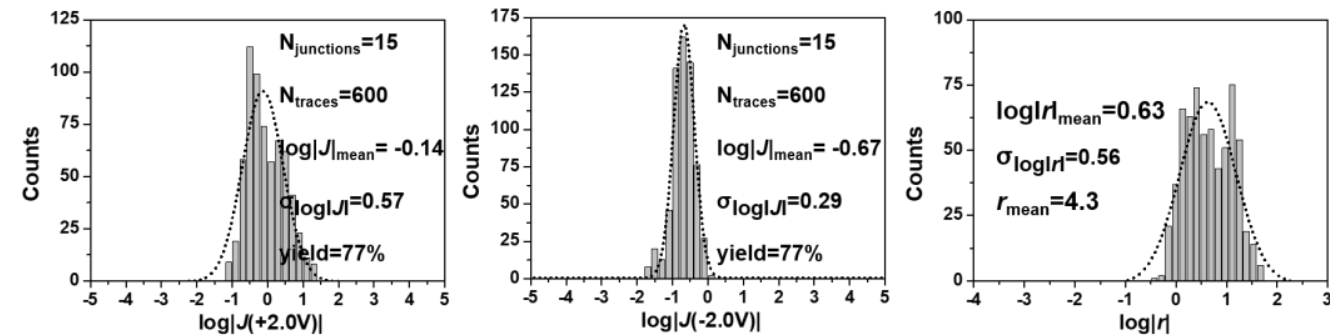

$2.5 \mathrm{~V}$
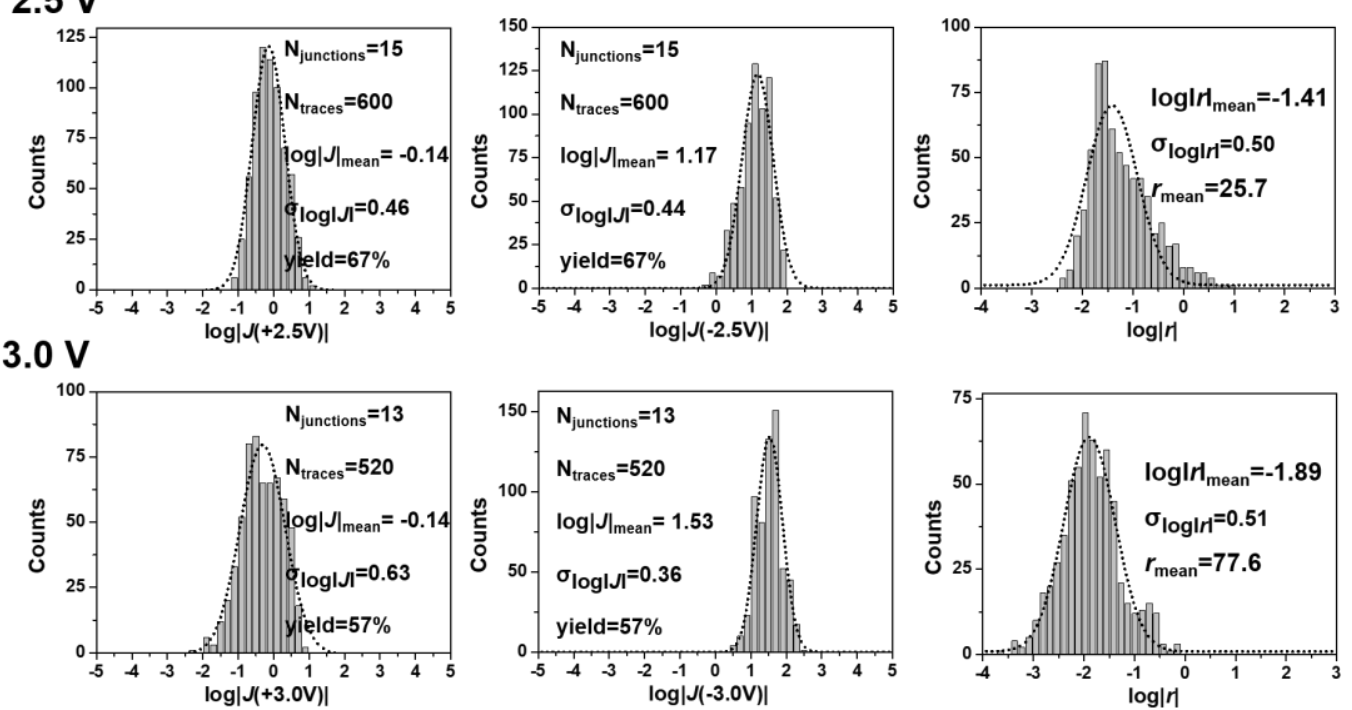

Figure S18. Histograms of $\log |J(V)|$ and $\log |r|$ values for $\operatorname{imSAM}^{2 \text { nd }}$ on $\mathrm{Au}^{\mathrm{TS}}$ as a function of external bias voltage. 
(a)
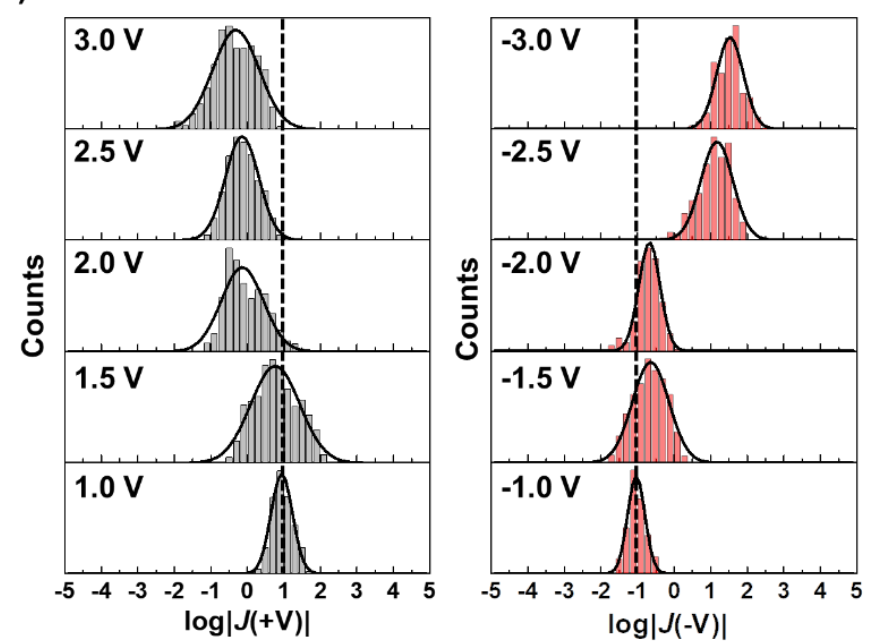

(b)

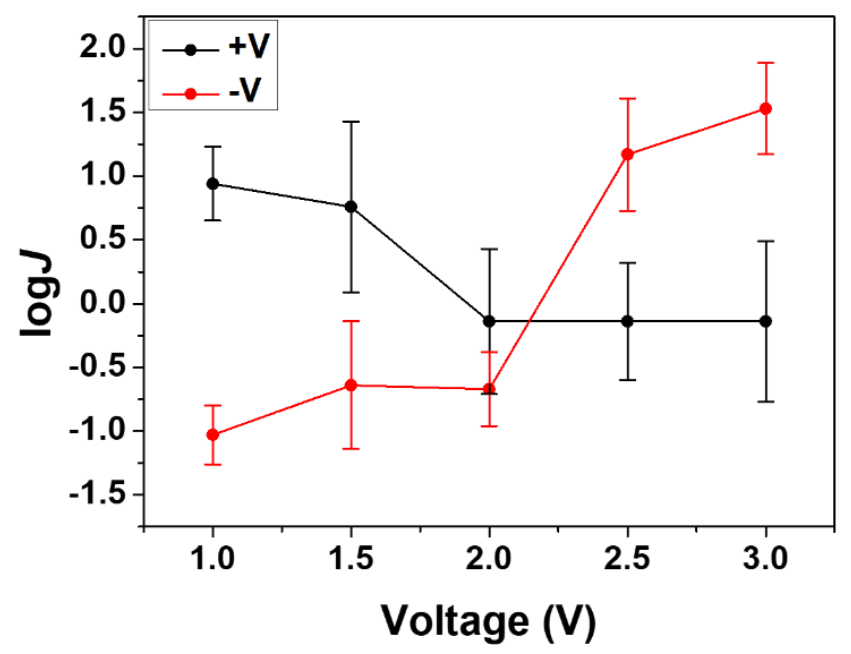

Figure S19. (a) Histograms and (b) $J-V$ plots of $\operatorname{imSAM}^{2 \text { nd }}$ as a function of external bias voltage. 
(a)

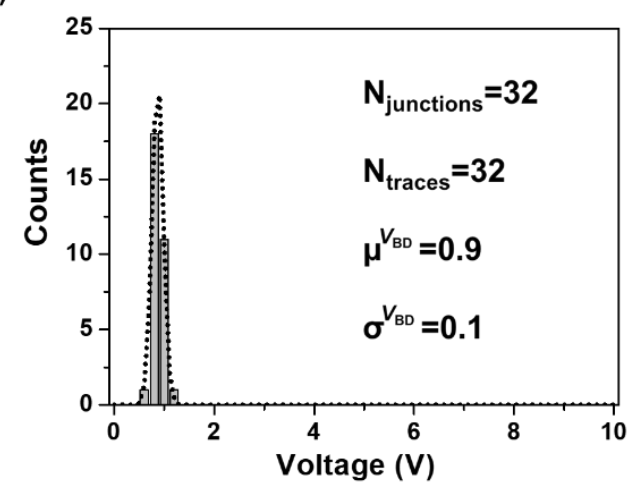

(c)

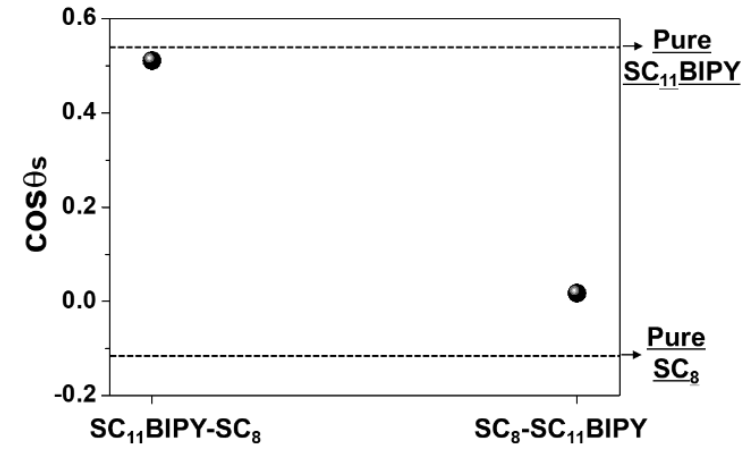

(b)

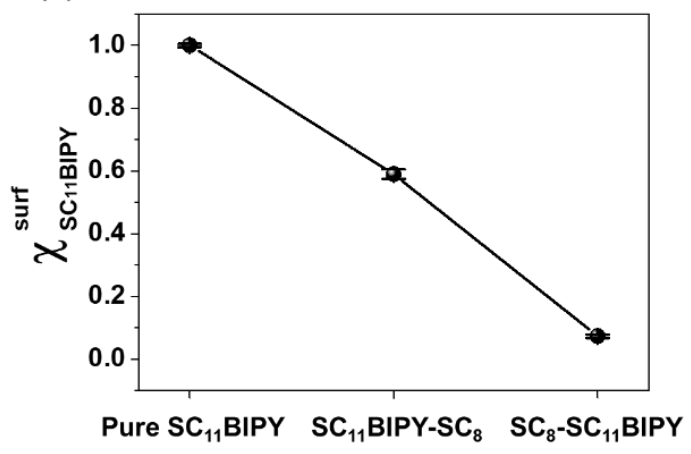

(d)

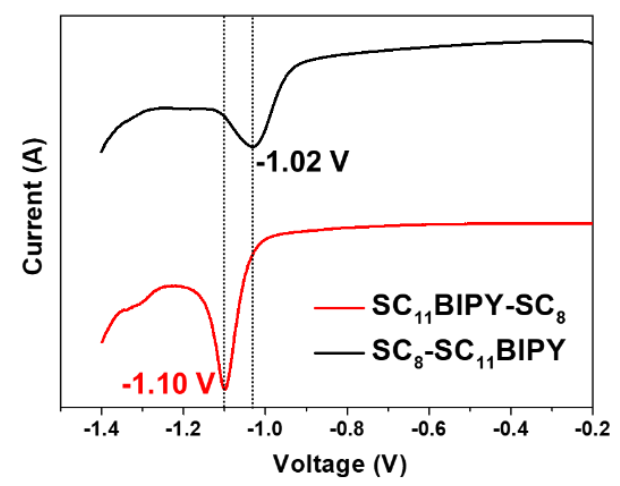

Figure S20. (a) Histogram of $V_{\mathrm{BD}}$ for the reversed system where matrix and reinforcement molecules are $\mathrm{HSC}_{8}$ and $\mathrm{HSC}_{11} \mathrm{BIPY}$, respectively). The SAM was formed on $\mathrm{Au}^{\mathrm{TS}}$ via two numbers of ReSEM cycles. Comparison among the reversed $\left(\mathrm{SC}_{8}-\mathrm{SC}_{11} \mathrm{BIPY}\right)$ and original (SC ${ }_{11}$ BIPY-SC 8$)$ mixed SAMs, and pure SAMs: (a) $\chi_{S C 11 B I P Y}^{\text {surf }}$, (b) static contact angle, and (c) reductive desorption. 

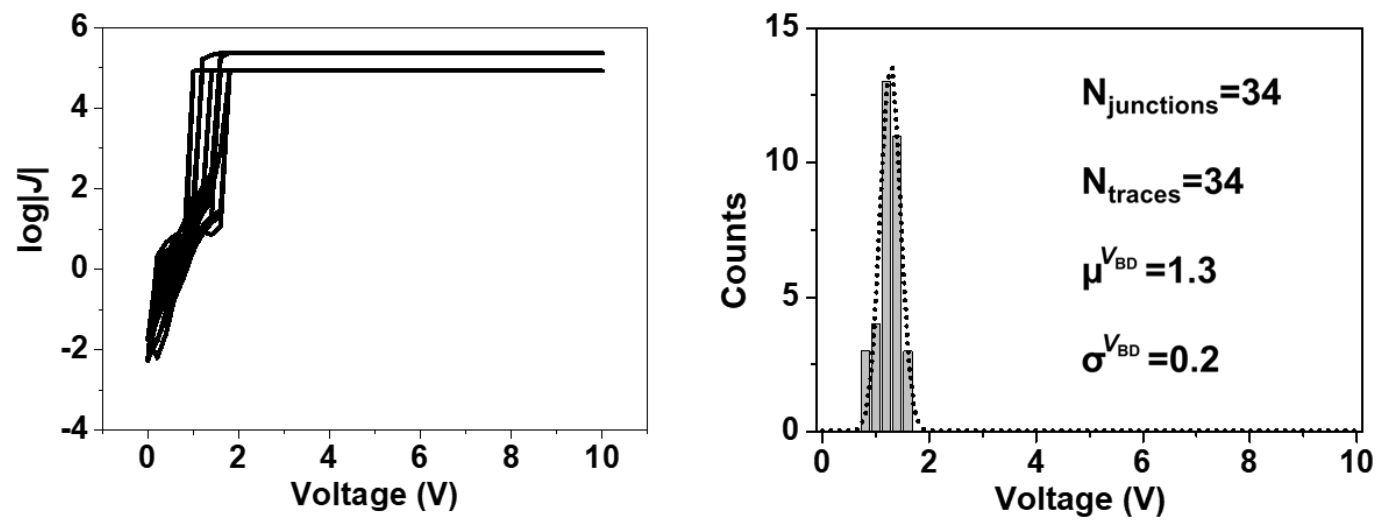

Figure S21. $J(V)$ traces and histograms of $V_{\mathrm{BD}}$ for pure $\mathrm{SC}_{11} \mathrm{BIPY} \mathrm{SAM}$ formed via two numbers of ReSEM cycles with pure ethanol solvent. 
Table S1. Summary of electrical characterization for pure $\mathrm{SC}_{8}$ and $\mathrm{SC}_{11} \mathrm{BIPY}$ SAMs and a series of mixed SAMs formed with HSC 11 BIPY and $\mathrm{HSC}_{8}$ on $\mathrm{Au}^{\mathrm{TS}}$ via different numbers of ReSEM cycles. The pure $\mathrm{SC}_{11} \mathrm{BPY}$ SAM is considered as single component SAM.

\begin{tabular}{|c|c|c|c|c|c|c|}
\hline & \multicolumn{3}{|c|}{$-V$} & \multicolumn{3}{|c|}{$+V$} \\
\hline & $\begin{array}{l}\text { Number of } \\
\text { junctions }\end{array}$ & $\begin{array}{c}\text { Number of } J-V \\
\text { traces }\end{array}$ & $\mu^{V_{B D}} \pm \sigma^{V_{B D}}$ & $\begin{array}{l}\text { Number of } \\
\text { junctions }\end{array}$ & $\begin{array}{c}\text { Number of } J-V \\
\text { traces }\end{array}$ & $\mu^{V_{B D}} \pm \sigma^{V_{B D}}$ \\
\hline Pure $\mathrm{SC}_{11} \mathrm{BIPY}$ & 32 & 32 & $-2.9 \pm 0.3$ & 35 & 35 & $1.4 \pm 0.3$ \\
\hline 1 cycle & 30 & 30 & $-3.0 \pm 0.1$ & 46 & 46 & $3.1 \pm 0.4$ \\
\hline 2 cycles & 29 & 29 & $-3.0 \pm 0.2$ & 40 & 40 & $3.3 \pm 0.3$ \\
\hline 3 cycles & 20 & 20 & $-2.9 \pm 0.1$ & 21 & 21 & $2.7 \pm 0.1$ \\
\hline $\mathrm{SC}_{8}$ & 29 & 29 & $-2.2 \pm 0.1$ & 36 & 36 & $0.7 \pm 0.2$ \\
\hline
\end{tabular}


Table S2. Summary of electrical characterization for mixed SAMs formed with $\mathrm{HSC}_{11} \mathrm{BIPY}$ and $\mathrm{HSC}_{8}$ on $\mathrm{Ag}^{\mathrm{TS}}$ and $\mathrm{Pt}^{\mathrm{TS}}$ via two ReSEM cycles.

\begin{tabular}{|c|c|c|c|c|c|c|}
\hline & \multicolumn{3}{|c|}{$-V$} & \multicolumn{3}{|c|}{$+V$} \\
\hline & $\begin{array}{c}\text { Number of } \\
\text { junctions }\end{array}$ & $\begin{array}{c}\text { Number of } J-V \\
\text { traces }\end{array}$ & $\mu^{V_{B D}} \pm \sigma^{V_{B D}}$ & $\begin{array}{c}\text { Number of } \\
\text { junctions }\end{array}$ & $\begin{array}{c}\text { Number of } J-V \\
\text { traces }\end{array}$ & $\mu^{V_{B D}} \pm \sigma^{V_{B D}}$ \\
\hline $\mathrm{Ag}^{\mathrm{TS}}$ & 14 & 14 & $-1.3 \pm 0.1$ & 22 & 22 & $1.2 \pm 0.1$ \\
\hline $\mathrm{Pt}^{\mathrm{TS}}$ & 18 & 18 & $-2.5 \pm 0.1$ & 38 & 38 & $2.5 \pm 0.1$ \\
\hline
\end{tabular}


Table S3. Summary of static water contact angle measurements for pure $\mathrm{SC}_{8}$ and $\mathrm{SC}_{11} \mathrm{BIPY}$ SAMs and a series of mixed SAMs formed with $\mathrm{HSC}_{11} \mathrm{BIPY}$ and $\mathrm{HSC}_{8}$ on $\mathrm{Au}^{\mathrm{TS}}$ via different numbers of ReSEM cycles.

\begin{tabular}{cc}
\hline & contact angle $(\theta)^{\mathrm{a}}$ \\
\hline $\mathrm{SC}_{11} \mathrm{BIPY}$ & Pure SAM \\
$\mathrm{HSC}_{8}$ & $59.9 \pm 0.5$ \\
& $97.0 \pm 3.5$ \\
\hline 1 cycle & ReSEM-processed SAM \\
2 cycles & $60.1 \pm 1.5$ \\
3 cycles & $59.3 \pm 1.3$ \\
\hline
\end{tabular}

${ }^{a}$ Averaged from eight separate measurements; error range is based on standard deviation. 
Table S4. Summary of dynamic contact angle measurements for pure $\mathrm{SC}_{8}$ and $\mathrm{SC}_{11} \mathrm{BIPY}$ SAMs and a series of mixed SAMs formed with $\mathrm{HSC}_{11} \mathrm{BIPY}$ and $\mathrm{HSC}_{8}$ on $\mathrm{Au}^{\mathrm{TS}}$ via different numbers of ReSEM cycles.

\begin{tabular}{|c|c|c|c|}
\hline & \multicolumn{3}{|c|}{ contact angle $(\theta)^{\mathrm{a}}$} \\
\hline & \multicolumn{3}{|c|}{ Pure SAM } \\
\hline & $\theta_{A}{ }^{\mathrm{a}}$ & $\theta_{R}{ }^{\mathrm{b}}$ & $\Delta \theta^{\mathrm{c}}$ \\
\hline $\mathrm{SC}_{11} \mathrm{BIPY}$ & $64.5 \pm 4.5$ & $49.7 \pm 7.7$ & $14.8 \pm 2.2$ \\
\hline \multirow[t]{3}{*}{$\mathrm{HSC}_{8}$} & $99.5 \pm 1.7$ & $91.2 \pm 3.8$ & $8.2 \pm 2.1$ \\
\hline & \multicolumn{3}{|c|}{ ReSEM-processed SAM } \\
\hline & $\theta_{A}{ }^{\mathrm{a}}$ & $\theta_{R}^{\mathrm{b}}$ & $\Delta \theta^{\mathrm{c}}$ \\
\hline 1 cycle & $60.8 \pm 1.5$ & $56.3 \pm 1.8$ & $4.5 \pm 0.3$ \\
\hline 2 cycles & $59.0 \pm 1.3$ & $55.0 \pm 1.6$ & $4.0 \pm 0.3$ \\
\hline 3 cycles & $64.4 \pm 0.4$ & $61.5 \pm 4.9$ & $2.9 \pm 4.5$ \\
\hline
\end{tabular}

${ }^{\mathrm{a} A d v a n c i n g}$ contact angle

${ }^{\mathrm{b}}$ Receding contact angle

${ }^{c}$ Averaged from eight separate measurements; error range is based on standard deviation. 
Table S5. Summary of \%EAS data for pure $\mathrm{SC}_{11} \mathrm{BIPY}$ SAM and a series of mixed SAMs formed with $\mathrm{HSC}_{11} \mathrm{BIPY}$ and $\mathrm{HSC}_{8}$ on $\mathrm{Au}^{\mathrm{TS}}$ via different numbers of ReSEM cycles.

\begin{tabular}{cc}
\hline & $\% \mathrm{EAS}^{\mathrm{a}}$ \\
\hline $\mathrm{SC}_{11}$ BIPY & Pure SAM \\
\hline 1 cycle & $2.4 \pm 0.2$ \\
\hline 2 cycles & ReSEM-processed SAM \\
3 cycles & $2.1 \pm 0.2$ \\
\hline
\end{tabular}

${ }^{a}$ Averaged from six measurements; error range is based on standard deviation. 
Table S6. Summary of surface coverage measurements for pure $\mathrm{SC}_{8}$ and $\mathrm{SC}_{11} \mathrm{BIPY}$ SAMs and a series of mixed SAMs formed with $\mathrm{HSC}_{11} \mathrm{BIPY}$ and $\mathrm{HSC}_{8}$ on $\mathrm{Au}^{\mathrm{TS}}$ via different numbers of ReSEM cycles.

\begin{tabular}{cc}
\hline & $\Gamma^{\mathrm{a}}$ \\
\hline & Pure SAM \\
\hline $\mathrm{SC}_{11} \mathrm{BIPY}$ & $5.1 \times 10^{-10} \pm 5.3 \times 10^{-11}$ \\
$\mathrm{HSC}_{8}$ & $7.5 \times 10^{-10} \pm 1.0 \times 10^{-10}$ \\
\hline & ReSEM-processed SAM \\
\hline 1 cycle & $9.8 \times 10^{-10} \pm 9.2 \times 10^{-11}$ \\
2 cycles & $1.43 \times 10^{-9} \pm 1.0 \times 10^{-10}$ \\
3 cycles & $1.46 \times 10^{-9} \pm 8.4 \times 10^{-11}$ \\
\hline
\end{tabular}

${ }^{a}$ Averaged from seven measurements; error range is based on standard deviation. 
Table S7. Summary of EIS data for pure $\mathrm{SC}_{11}$ BIPY SAM and a series of mixed SAMs formed with $\mathrm{HSC}_{11} \mathrm{BIPY}$ and $\mathrm{HSC}_{8}$ on $\mathrm{Au}^{\mathrm{TS}}$ via different numbers of ReSEM cycles.

\begin{tabular}{cc}
\hline & $-\varphi_{1 \mathrm{~Hz}}{ }^{\mathrm{a}}$ \\
\hline & Pure SAM \\
\hline SC $_{11}$ BIPY & $73.2 \pm 6.0$ \\
\hline 1 cycle & ReSEM-processed SAM \\
2 cycles & $81.7 \pm 2.8$ \\
3 cycles & $86.3 \pm 0.7$ \\
\hline
\end{tabular}

${ }^{a}$ Averaged from seven measurements; error range is based on standard deviation. 
Table S8. Comparison of experimental thicknesses for pure $\mathrm{SC}_{11} \mathrm{BIPY}$ SAM and imSAM ${ }^{2 \mathrm{nd}}$ using ellipsometer.

\begin{tabular}{cc}
\hline & Thickness \\
\hline Pure SC $_{11}$ BIPY & $1.742 \mathrm{~nm}$ \\
imSAM $^{2 \text { nd }}$ & $1.877 \mathrm{~nm}$ \\
\hline
\end{tabular}


Table S9. Summary of electrical characterization for imSAM ${ }^{\text {nd }}$ on $\mathrm{Au}^{\mathrm{TS}}$.

\begin{tabular}{|c|c|c|c|c|c|c|}
\hline$|\boldsymbol{V}|$ & $\begin{array}{l}\text { Number of } \\
\text { junctions }\end{array}$ & $\begin{array}{l}\text { Number of } \\
J-V \text { traces }\end{array}$ & $\begin{array}{l}\text { Yield of working } \\
\text { junctions }(\%)\end{array}$ & $\log |J(+V)|_{\text {mean }} \pm \sigma_{\log |J|}$ & $\log |J(-V)|$ mean $\pm \sigma_{\log |J|}$ & $\begin{array}{l}\log \left|r^{+}\right|_{\text {mean }} \pm \sigma_{\log |r+|} \\
\left(\left|r^{+}\right| \text {mean } \pm \sigma_{|r+|}\right)\end{array}$ \\
\hline $1.0 \mathrm{~V}$ & 15 & 600 & 92 & $0.9 \pm 0.3$ & $-1.0 \pm 0.2$ & $\begin{array}{l}2.0 \pm 0.1 \\
(93.3 \pm 1.3)\end{array}$ \\
\hline $1.5 \mathrm{~V}$ & 15 & 600 & 92 & $0.8 \pm 0.7$ & $-0.6 \pm 0.5$ & $\begin{array}{l}1.4 \pm 0.2 \\
(25.1 \pm 1.6)\end{array}$ \\
\hline $2.0 \mathrm{~V}$ & 15 & 600 & 77 & $-0.1 \pm 0.6$ & $-0.7 \pm 0.3$ & $\begin{array}{l}0.6 \pm 0.6 \\
(4.3 \pm 4.0)\end{array}$ \\
\hline $2.5 \mathrm{~V}$ & 15 & 600 & 67 & $-0.1 \pm 0.5$ & $1.2 \pm 0.4$ & $\begin{array}{l}-1.4 \pm 0.5 \\
(-25.7 \pm 3.2)\end{array}$ \\
\hline $3.0 \mathrm{~V}$ & 13 & 520 & 57 & $-0.1 \pm 0.6$ & $1.5 \pm 0.4$ & $\begin{array}{l}-1.9 \pm 0.5 \\
(-77.6 \pm 3.2)\end{array}$ \\
\hline
\end{tabular}




\section{References}

1 Yoon, H. J. et al. Rectification in tunneling junctions: 2,2 '-Bipyridyl-terminated $n$ alkanethiolates. J. Am. Chem. Soc. 136, 17155-17162 (2014).

2 Kong, G. D., Kim, M., Jang, H. J., Liao, K. C. \& Yoon, H. J. Influence of halogen substitutions on rates of charge tunneling across SAM-based large-area junctions. Phys. Chem. Chem. Phys. 17, 13804-13807 (2015).

3 Simeone, F. C. et al. Defining the value of injection current and effective electrical contact area for EGaln-based molecular tunneling junctions. J. Am. Chem. Soc. 135, 18131-18144 (2013).

4 Kong, G. D., Kim, M., Cho, S. J. \& Yoon, H. J. Gradients of rectification: Tuning molecular electronic devices by the controlled use of different-sized diluents in heterogeneous selfassembled monolayers. Angew. Chem., Int. Ed. 55, 10307-10311 (2016).

5 Reus, W. F. et al. Statistical tools for analyzing measurements of charge transport. J. Phys. Chem. C 116, 6714-6733 (2012).

6 Kong, G. D. et al. Elucidating the Role of Molecule-Electrode Interfacial Defects in Charge Tunneling Characteristics of Large-area Junctions. J. Am. Chem. Soc. 140, 12303-12307 (2018).

7 Laiho, T., Leiro, J. A., Heinonen, M. H., Mattila, S. S. \& Lukkari, J. Photoelectron spectroscopy study of irradiation damage and metal-sulfur bonds of thiol on silver and copper surfaces. J. Electron Spectrosc. Relat. Phenom. 142, 105-112 (2005).

8 Nelson, K. E. et al. Surface characterization of mixed self-assembled monolayers designed for streptavidin immobilization. Langmuir 17, 2807-2816 (2001).

9 Folkers, J. P., Laibinis, P. E. \& Whitesides, G. M. Self-assembled monolayers of alkanethiols on gold: Comparisons of monolayers containing mixtures of short- and long-chain constituents with methyl and hydroxymethyl terminal groups. Langmuir 8, 1330-1341 (1992).

10 Schoenfisch, M. H. \& Pemberton, J. E. Air stability of alkanethiol self-assembled monolayers on silver and gold surfaces. J. Am. Chem. Soc. 120, 4502-4513 (1998).

11 Schneider, T. W. \& Buttry, D. A. Electrochemical quartz crystal microbalance studies of adsorption and desorption of self-assembled monolayers of alkyl thiols on Gold. J. Am. Chem. Soc. 115, 12391-12397 (1993).

12 Walczak, M. M. et al. Reductive desorption of alkanethiolate monolayers at gold: A measure of surface coverage. Langmuir 7, 2687-2693 (1991).

13 Brooks, B. R. et al. CHARMM: The Biomolecular Simulation Program. J. Comput. Chem. 30, 1545-1614 (2009).

14 Kang, H., Kim, Y., Choi, I., Chang, R. \& Yeo, W.-S. Determination of self-exchange rate of alkanethiolates in self-assembled monolayers on gold using matrix-assisted laser desorption/ionization time-of-flight mass spectrometry. Anal. Chim. Acta. 843, 38-45 (2014).

15 Vanommeslaeghe, K. et al. CHARMM general force field: A force field for drug-like molecules compatible with the CHARMM all-atom additive biological force fields. $J$. Comput. Chem. 31, 671-690 (2010).

16 Feller, S. E., Zhang, Y., Pastor, R. W. \& Brooks, B. R. Constant pressure molecular dynamics simulation: The langevin piston method. J. Chem. Phys. 103, 4613-4621 (1995).

17 Hoover, W. G. Canonical dynamics: Equilibrium phase-space dDistributions. Phys. Rev. A 31, 1695 (1985).

18 Arihara, K. et al. Multiple voltammetric waves for reductive desorption of cysteine and 4mercaptobenzoic acid monolayers self-assembled on gold substrates. Phys. Chem. Chem. Phys. 5, 3758-3761 (2003).

19 Doneux, T., Steichen, M., De Rache, A. \& Buess-Herman, C. Influence of the crystallographic orientation on the reductive desorption of self-assembled monolayers on gold electrodes. J. Electroanal. Chem. 649, 164-170 (2010). 